\title{
Sleep disturbances in women with polycystic ovary syndrome: prevalence, pathophysiology, impact and management strategies
}

REVIEW

This article was published in the following Dove Press journal:

Nature and Science of Sleep

\author{
Renae C Fernandez ${ }^{1-3}$ \\ Vivienne M Moore ${ }^{1,3,4}$ \\ Emer MVan Ryswyk ${ }^{5}$ \\ Tamara J Varcoe ${ }^{1,2}$ \\ Raymond J Rodgers ${ }^{1,2}$ \\ Wendy A March 1,3 \\ Lisa J Moran ${ }^{1,6}$ \\ Jodie C Avery ${ }^{1,2}$ \\ R Doug McEvoy ${ }^{5,7}$ \\ Michael J Davies ${ }^{1,2}$
}

'The University of Adelaide, Robinson Research Institute, Adelaide, SA, Australia; ${ }^{2}$ The University of Adelaide, Adelaide Medical School, Adelaide, SA, Australia; ${ }^{3}$ The University of Adelaide, School of Public Health, Adelaide, SA, Australia; ${ }^{4}$ The University of Adelaide, Fay Gale Centre for

Research on Gender, Adelaide, SA, Australia; ${ }^{5}$ Adelaide Institute for Sleep Health, Flinders Centre for Research Excellence, Flinders University of South Australia, Bedford Park, SA, Australia; ${ }^{6}$ Monash Centre for Health Research Implementation, School of Public Health and Preventive Medicine, Monash University, Melbourne, Vic, Australia; ${ }^{7}$ Adelaide Sleep Health, Southern Adelaide Local Health Network, Repatriation General Hospital, Daw Park, SA, Australia

Correspondence: Renae C Fernandez Life Course and Intergenerational Health Research Group, University of Adelaide, GPO Box 498, Adelaide SA 5005, Australia

Tel +61883130152

Email renae.fernandez@adelaide.edu.au

\begin{abstract}
Polycystic ovary syndrome (PCOS) is a complex endocrine disorder affecting the reproductive, metabolic and psychological health of women. Clinic-based studies indicate that sleep disturbances and disorders including obstructive sleep apnea and excessive daytime sleepiness occur more frequently among women with PCOS compared to comparison groups without the syndrome. Evidence from the few available population-based studies is supportive. Women with PCOS tend to be overweight/obese, but this only partly accounts for their sleep problems as associations are generally upheld after adjustment for body mass index; sleep problems also occur in women with PCOS of normal weight. There are several, possibly bidirectional, pathways through which PCOS is associated with sleep disturbances. The pathophysiology of PCOS involves hyperandrogenemia, a form of insulin resistance unique to affected women, and possible changes in cortisol and melatonin secretion, arguably reflecting altered hypothalamic-pituitary-adrenal function. Psychological and behavioral pathways are also likely to play a role, as anxiety and depression, smoking, alcohol use and lack of physical activity are also common among women with PCOS, partly in response to the distressing symptoms they experience. The specific impact of sleep disturbances on the health of women with PCOS is not yet clear; however, both PCOS and sleep disturbances are associated with deterioration in cardiometabolic health in the longer term and increased risk of type 2 diabetes. Both immediate quality of life and longer-term health of women with PCOS are likely to benefit from diagnosis and management of sleep disorders as part of interdisciplinary health care.
\end{abstract}

Keywords: polycystic ovary syndrome, sleep, sleep disturbance, hypothalamic-pituitary-adrenal, cardiometabolic health

\section{Introduction}

Polycystic ovary syndrome (PCOS) is a complex endocrine disorder with implications for reproductive, psychological and metabolic health. Despite first being identified in the 1930s, recognition of an association between PCOS and sleep disturbances is relatively recent. A search of the PubMed database indicates that the majority of research on this topic has been published after 2005 and the body of work remains quite small (Figure 1).

In this review, we first provide an overview of PCOS and summarize the clinical and epidemiological literature pertaining to sleep disturbances and disorders among women with the condition. The pathways through which PCOS may influence sleep are then described in detail, focusing on the endocrine, psychosocial and behavioral characteristics that are often present among women with PCOS, drawing attention to probable bidirectional relationships (Figure 2). Current knowledge about the long-term http:/dd

(c) (7) (5) 2018 Fernandez et al. This work is published and licensed by Dove Medical Press Limited. The full terms of this license are available at https://www.dovepress.com/terms.

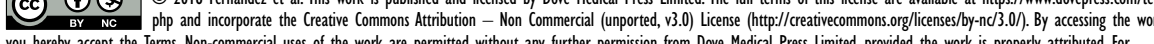
you hereby accept the Terms. Non-commercial uses of the work are permitted without any further permission from Dove Medical Press Limited, provided the work is properly attributed. For permission for commercial use of this work, please see paragraphs 4.2 and 5 of our Terms (https://www.dovepress.com/ttrms.php). 


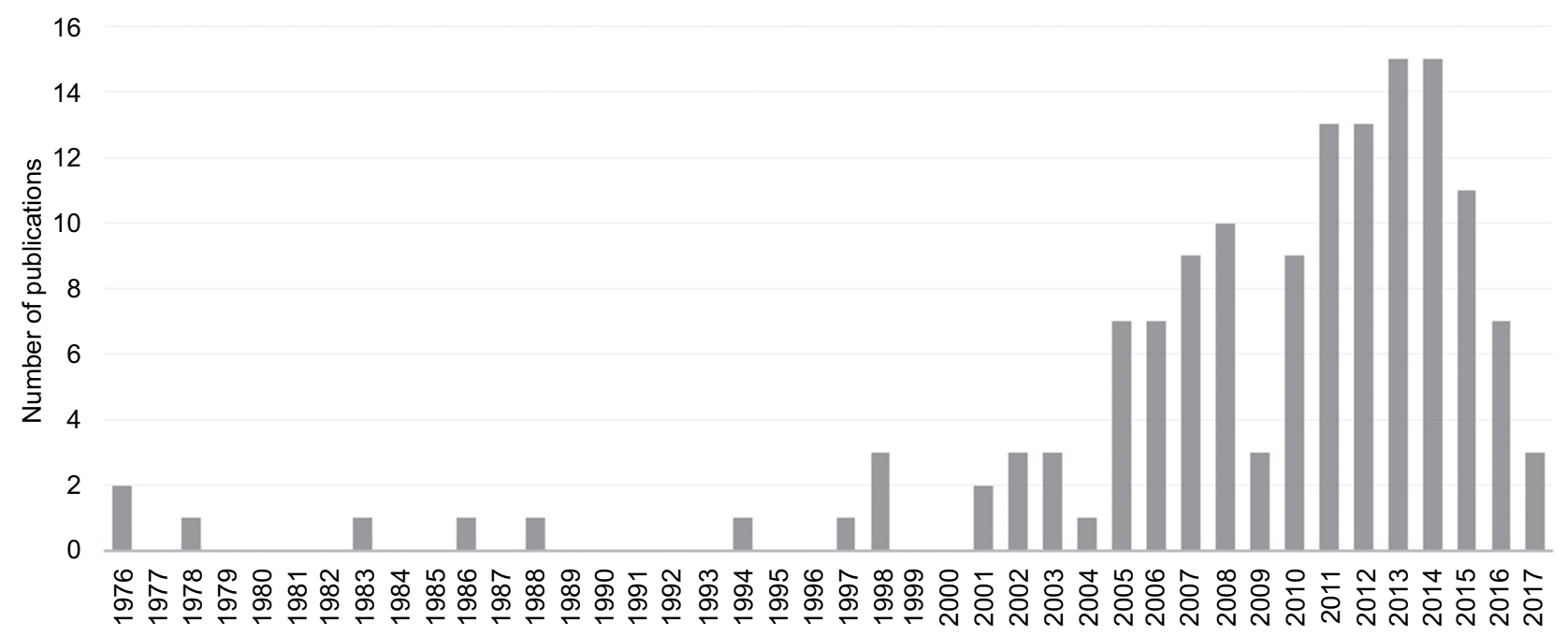

Figure I The number of articles published in PubMed per year on the topic of PCOS and sleep. Abbreviation: PCOS, polycystic ovary syndrome.

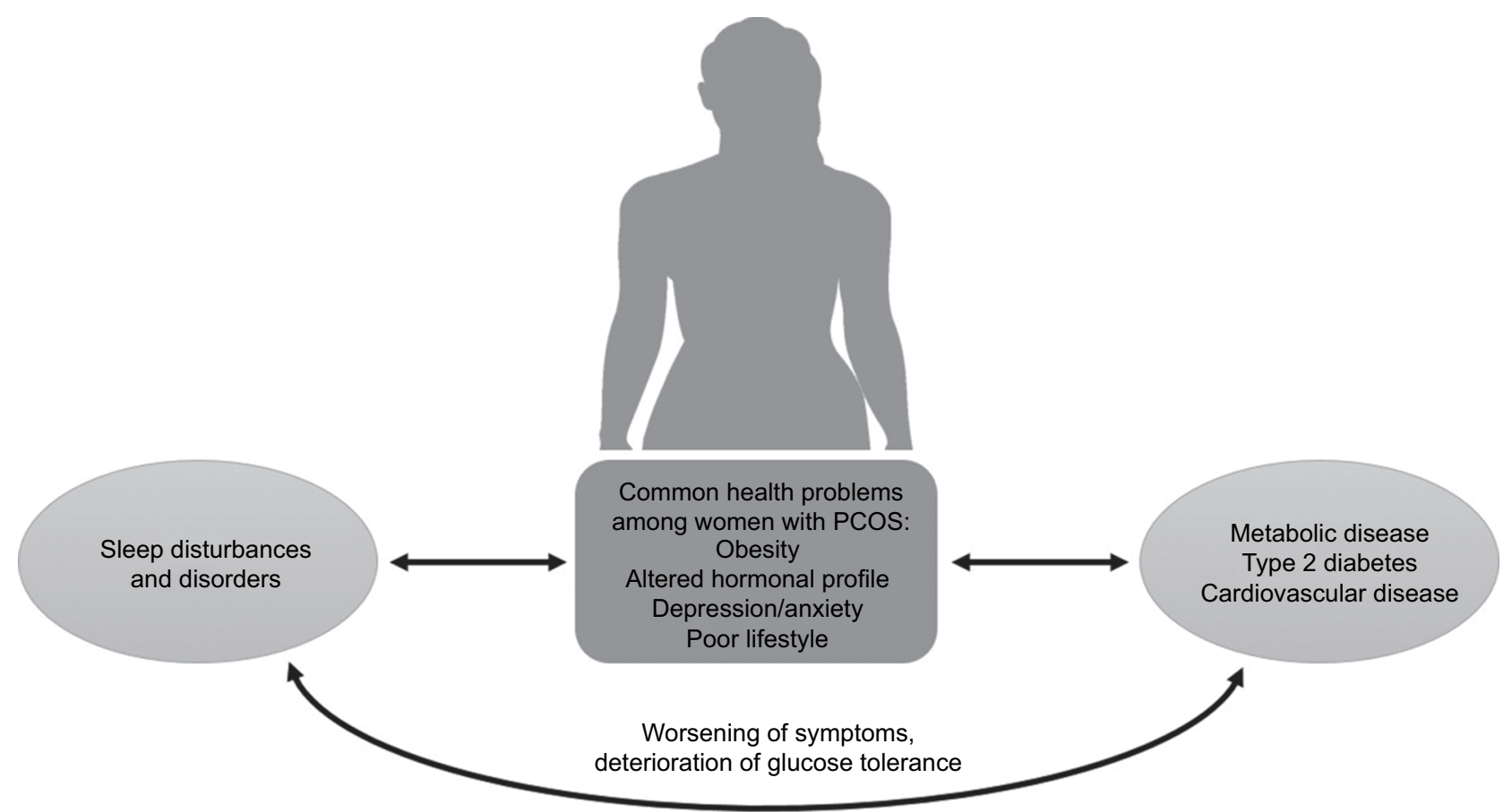

Figure 2 Summary of the bidirectional pathways through which PCOS interacts with sleep disturbances, with potentially detrimental effects on long-term cardiometabolic health.

Abbreviation: PCOS, polycystic ovary syndrome.

consequences of PCOS for cardiometabolic health is outlined as well as the potential contribution of impaired sleep to deterioration of health profiles.

\section{Polycystic ovary syndrome}

PCOS is an endocrine disorder that manifests in an array of symptoms that varies from one woman to another. ${ }^{1}$ This heterogeneity has hampered the definition of the syndrome, etiological research, recognition in clinical practice and appropriate treatment and support for women.

PCOS was first recognized as a clinical entity in the 1930s. At that time it was named Stein-Leventhal syndrome, after the two clinicians who first reported the disorder in seven women who presented with hirsutism, amenorrhea and 
enlarged bilateral polycystic ovaries, along with obesity. ${ }^{2,3}$ Once considered a reproductive disorder acquired by adult women, it is now widely accepted that PCOS is a lifelong metabolic condition. ${ }^{4}$

Features of the syndrome classically emerge during puberty, but diagnosis can be difficult because irregular menstruation is common in normal development. ${ }^{1,5}$ Excess body hair accumulates gradually, reflecting increasing duration of androgen exposure. Some girls (and women) with PCOS have severe acne vulgaris (predominantly on the lower face, neck, chest and upper back). ${ }^{1}$

Historically, recognition of PCOS by clinicians was erratic. ${ }^{6,7}$ In addition, reluctance to seek medical advice (e.g. due to embarrassment) meant that many women did not receive a diagnosis until they sought fertility treatment, or lifelong. ${ }^{8}$ Undiagnosed PCOS is still relatively common. ${ }^{9}$

Currently, there are three sets of criteria for diagnosing PCOS, summarized in Figure 3. Differences between the criteria reflect controversy about the pathogenesis of PCOS and the different forums in which experts' opinions were canvassed. ${ }^{3}$ In 1990, experts at a conference sponsored by the US National Institutes of Health (NIH) produced the first attempt at defining PCOS clinically. The NIH criteria specify (in order of importance) that clinical and/or biochemical signs of hyperandrogenism should be present as well as oligo- or anovulation (i.e. irregular or no periods). ${ }^{10}$ In 2003, the European Society of Human Reproduction and Embryology and the American Society for Reproductive Medicine produced a statement, known as the Rotterdam criteria, specifying that two out of the following three must be met for a diagnosis of PCOS: clinical and/or biochemical hyperandrogenism, oligo- or anovulation and polycystic ovaries on ultrasound..$^{11}$ In 2006, the Androgen Excess Society (AES) Taskforce produced criteria specifying that hyperandrogenism must be present for diagnosis, in addition to either oligo- or anovulation or polycystic ovaries on ultrasound (or both). ${ }^{12}$ There have been several attempts to subclassify the syndrome using clinical and metabolic criteria, without universal agreement. ${ }^{3,13}$

All diagnostic criteria specify that diagnosis of PCOS should only be made after exclusion of other endocrine disorders including congenital adrenal hyperplasia, androgensecreting tumors, Cushing's syndrome, thyroid dysfunction and hyperprolactinemia. Early studies of women with PCOS suggested they had elevated prolactin, and explored overlap in symptoms between hyperprolactinemia and PCOS, but these are now considered to be two distinct conditions. ${ }^{14-18}$

Beyond the enlargement of ovaries originally noted by Stein and Leventhal, ${ }^{2}$ ovaries with multiple cysts (follicles with arrested development) have other features, including a thickened covering capsule and greatly increased stromal tissue. The thecal and stromal layers produce excess androgen, and this led to the view that pathogenesis is primarily ovarian. ${ }^{19}$ While recognizing wider metabolic involvement, the AES takes the position that PCOS is primarily a disorder of hyperandrogenism. ${ }^{12}$ Lack of consensus on this matter persists because hormone signaling has a major role in systems such as the hypothalamic-pituitary-adrenal (HPA) axis, so the disorder could have a central origin, and there are conflicting results from interventions in which androgens were

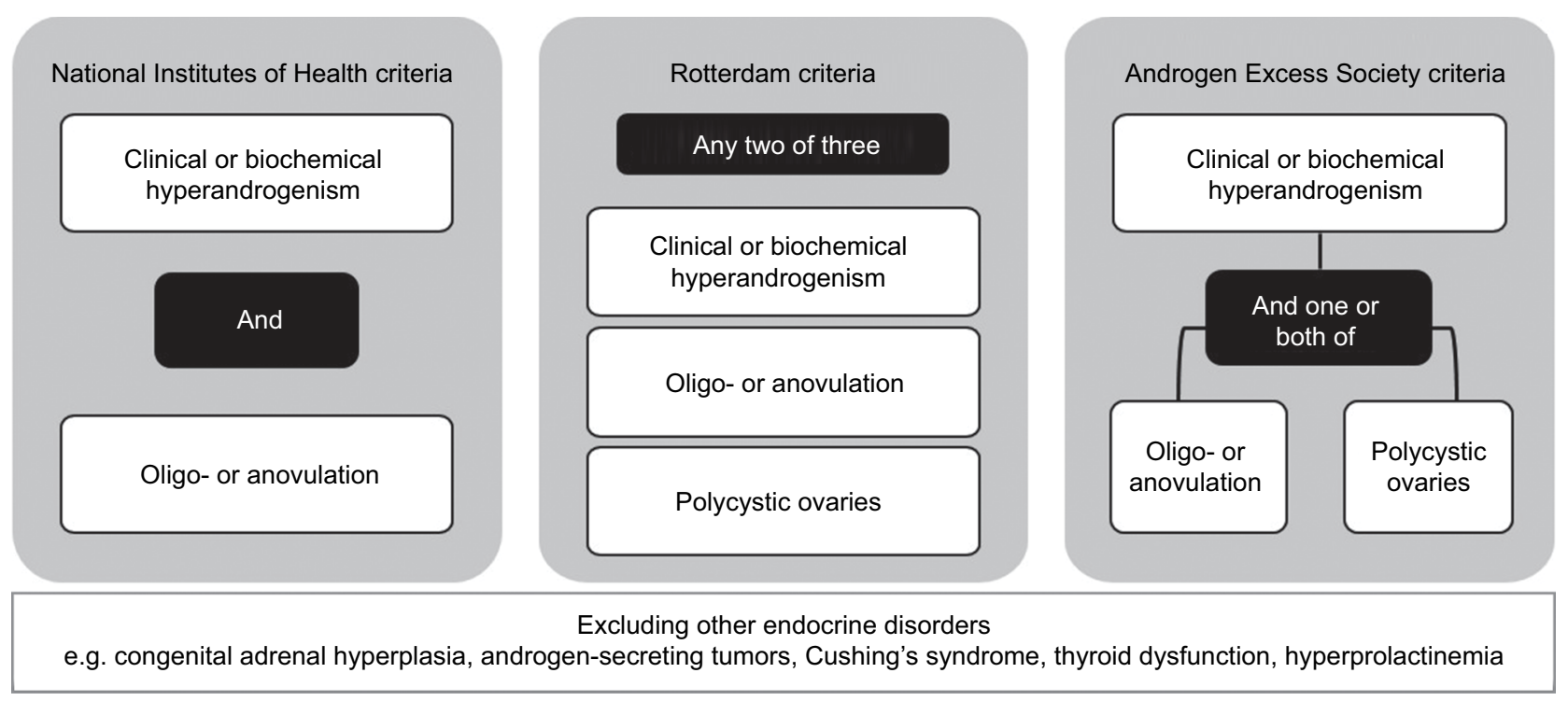

Figure 3 A summary of the three sets of criteria for the diagnosis of PCOS: the National Institutes of Health criteria (1990), ${ }^{10}$ the Rotterdam criteria (2003) ${ }^{11}$ and the Androgen Excess Society criteria (2006). ${ }^{12}$

Abbreviation: PCOS, polycystic ovary syndrome. 
reduced in women with $\mathrm{PCOS} .^{3}$ Additionally, constructive debate is impeded by lack of a reliable assay designed to measure androgens in the range relevant to women, approximately one-tenth that of men. ${ }^{20,21}$

Research undertaken in the 1980s demonstrated insulin resistance in women with PCOS, underpinning the alternative view that this is the cardinal feature of the syndrome, with hyperinsulinemia causing hyperandrogenemia and anovulation. ${ }^{3}$ Even lean women with PCOS generally have insulin resistance of an intrinsic form, ${ }^{22}$ which appears to be the result of a defect in post-binding insulin signaling that disturbs metabolic but not mitogenic functions. ${ }^{23}$ This abnormality appears unique to PCOS, as it has not been observed in other conditions of insulin resistance, including obesity and type 2 diabetes. ${ }^{24}$ Thus, when women with PCOS have high body weight, they are affected by both intrinsic and extrinsic insulin resistance. ${ }^{3}$ PCOS has recently been conceptualized as a condition of severe metabolic stress, ${ }^{25}$ a position that we support as it provides a way to account for the pervasive molecular and biochemical derangements that occur in PCOS and variation in symptom profiles.

Clustering of diagnosed PCOS and isolated hormonal and metabolic symptoms within families supports a genetic component to the etiology of PCOS $;{ }^{26}$ however, phenotypic variation suggests that multiple genes are involved. ${ }^{27}$ Familial and cohort studies have identified numerous gene loci as candidates for conferring susceptibility to PCOS. These include polymorphisms in loci associated with androgen receptors and with insulin signaling. For many of the candidate loci, it remains unclear as to how they relate to specific PCOS characteristics. $^{27}$

Support for fetal or early life origins of PCOS stems from animal models in which exposure to androgen excess, or growth restriction or acceleration, has produced symptoms of PCOS. ${ }^{3,28}$ It is unlikely that maternal androgens reach the fetus in human pregnancies, although fetal ovarian androgen production is possible. ${ }^{3}$ Birth phenotypes in humans have consistently been associated with insulin resistance, type 2 diabetes and the metabolic syndrome. ${ }^{29-32}$

While we accept a genetic contribution, our research ${ }^{33,34}$ is premised on interactions with the fetal environment producing epigenetic changes that culminate in PCOS. ${ }^{35}$ Hypothesized "programming" of metabolic function is not simply about growth of the fetus or size at birth, although these are overt signs of perturbed development in utero. ${ }^{36} \mathrm{~A}$ range of conditions, including maternal under- and overnutrition and mental distress, can inhibit the activity of an enzyme in the placenta (11 beta-hydroxysteroid dehydrogenase) that is critical to reducing fetal exposure to maternal glucocorticoids. ${ }^{37}$ Through this process, it is proposed that overexposure of the fetus alters the set points and function of the HPA axis, with profound implications for metabolism.

Uncertainties about PCOS also persist because it is difficult to study in representative population-based samples of women. Obtaining self-reports of doctor-diagnosed PCOS will result in misclassification of a substantial proportion of women as unaffected. Some symptoms can be reported reliably but others require invasive tests, and the sensitive nature of symptoms may affect participation. Thus, few studies with community-based samples have been undertaken to date, although clinic-based samples have been reported on extensively.

We retrospectively established a birth cohort of Australian women using records from a large maternity hospital. ${ }^{9}$ We traced over $90 \%$ of 2199 female babies three decades after they were born. Around half of the young women who were eligible joined the study and completed an initial interview in which medical and reproductive history, including symptoms of PCOS, were reported. Women were asked to provide a blood sample for assessment of free testosterone. Those with evidence of both hyperandrogenism and oligo- or anovulation were classified as having PCOS as per the NIH criteria. Women with one or both of those two symptoms were referred to a clinic for ovarian ultrasound so that we could apply the Rotterdam criteria. The prevalence of PCOS was $8.7 \pm 2.0 \%$ with NIH criteria, $11.9 \pm 2.4 \%$ with Rotterdam criteria assuming those who did not consent to ultrasound did not have cystic ovaries and $17.8 \pm 2.8 \%$ with Rotterdam criteria using multiple imputation for missing ultrasound data. Over two-thirds of those classified as having PCOS had not been diagnosed previously.

\section{Sleep disturbances and disorders and PCOS}

Sleep disturbances include altered sleep duration, delay of sleep onset, difficulty in maintaining sleep or awakening early. ${ }^{38}$ Insomnia is defined as impairment in the ability to initiate or maintain sleep, including extended periods of wakefulness during the night. Chronic insomnia disorder is diagnosed when insomnia occurs at least three nights per week and for at least three months. ${ }^{39}$ Obstructive sleep apnea (OSA) is characterized by frequent cessations of breathing during sleep and may occur along with other sleep disturbances. ${ }^{40}$ Clinically, OSA is diagnosed by detecting the frequency of events that are apneic (no airflow for 10 seconds) and hypopneic (decreased airflow for 10 seconds 
associated with either an oxyhemoglobin desaturation or an arousal detected by electroencephalography), as per the apnea-hypopnea index (AHI). A diagnosis of OSA is made when $\mathrm{AHI}$ is $\geq 15$ or when $\mathrm{AHI}$ is $\geq 5$ with symptoms such as daytime sleepiness, loud snoring and witnessed breathing interruptions. $^{41}$

Sleep disturbances and disorders have repercussions for daytime mood, cognition and psychomotor functioning, ${ }^{42}$ which acutely affect well-being and daily activities, and can inhibit performance in roles such as that of parent or employee. ${ }^{43,44}$ Aspects of cognition that appear most affected are attention, executive function and working memory, ${ }^{42,45}$ with significant implications for productivity. ${ }^{44}$ Fatigue, attention deficits and psychomotor impairment can affect safety, increasing the risk of workplace and motor vehicle accidents. ${ }^{42}$ Thus, poor sleep represents a serious health problem.

As mentioned, it is difficult to study PCOS in representative population-based samples; so evidence concerning the prevalence of sleep disturbances and disorders across the full spectrum of PCOS severity is limited. We identified only three such studies (Table 1), summarized here, each supporting an excess of sleep disturbances and disorders in women with PCOS that was not accounted for by obesity.

Two studies have drawn on the Taiwan National Health Insurance Research Database in which PCOS and sleep disorders were recorded using International Classification of Diseases codes (and thus required recognition and formal diagnosis). ${ }^{46}$ In a longitudinal design, data for women with PCOS $(n=4595)$ and a comparison group of women matched for age $(n=4595)$ were assembled over $2-8$ years. Women with PCOS had greater incidence of OSA (1.71 vs 0.63 per 1000 person-years), a difference not due to obesity or demographic characteristics (adjusted hazard ratio [HR] $=2.6,95 \%$ confidence interval $[\mathrm{CI}] 1.6-4.0)$. In the second study, sleep disorders excluding OSA were considered as part of an investigation of PCOS and psychiatric disorders..$^{47}$ Over a 10-year period, compared to an age-matched comparison group of women $(n=21,724)$, those with PCOS $(n=5431)$ were $50 \%$ more likely to be diagnosed with a sleep disorder $(\mathrm{HR}=1.5,95 \%$ CI 1.2-1.9).

In the community-based cohort of Australian women that we undertook, sleep disturbances were self-reported using a modified version of the Jenkins questionnaire, ${ }^{48}$ by 87 women with PCOS (as per Rotterdam criteria) and 637 women of similar age. ${ }^{48}$ Sleep disturbances, specifically difficulty falling asleep (odds ratio $[\mathrm{OR}]=1.9,95 \%$ CI 1.3-3.0) and difficulty maintaining sleep $(\mathrm{OR}=1.9,95 \% \mathrm{CI} 1.1-3.3)$, were twice as common in women with PCOS compared to those without. The former association persisted after accounting for body mass index (BMI) and depressive symptoms, but

Table I Summary of population- and community-based studies of sleep disturbances and PCOS in women

\begin{tabular}{|c|c|c|c|c|}
\hline Study, country & Study design & Study groups & $\begin{array}{l}\text { Outcomes of } \\
\text { interest }\end{array}$ & Key results \\
\hline $\begin{array}{l}\text { Hung et al, }{ }^{47} \\
\text { Taiwan }\end{array}$ & $\begin{array}{l}\text { Retrospective } \\
\text { cohort constructed } \\
\text { from the National } \\
\text { Health Insurance } \\
\text { Database }(98 \% \\
\text { coverage) }\end{array}$ & $\begin{array}{l}5431 \text { with PCOS } \\
\text { and } 21,724 \\
\text { without PCOS } \\
\text { matched for age }\end{array}$ & $\begin{array}{l}\text { Diagnosis of new- } \\
\text { onset sleep disorders: } \\
\text { ICD-9 } 780.5 \\
\text { (insomnias) and } 307.4 \\
\text { (difficulty initiating } \\
\text { and maintaining sleep, } \\
\text { excluding OSA) }\end{array}$ & $\begin{array}{l}\text { - Women with PCOS were more likely to be diagnosed } \\
\text { with sleep disorders: HR = I.495 (95\% CI I.I76-I.899) } \\
\text { - Most developed in the first year since diagnosis of PCOS }\end{array}$ \\
\hline $\begin{array}{l}\text { Lin et al, }{ }^{46} \\
\text { Taiwan }\end{array}$ & & $\begin{array}{l}4595 \text { with PCOS } \\
\text { and } 4595 \text { without } \\
\text { PCOS matched } \\
\text { for age and time } \\
\text { of enrollment }\end{array}$ & $\begin{array}{l}\text { Diagnosis of OSA } \\
\text { during follow-up }(2-13 \\
\text { years) }\end{array}$ & $\begin{array}{l}\text { - Women with PCOS had a greater incidence of OSA } \\
\text { (I.7I vs } 0.63 \text { per } 1000 \text { person-years) } \\
\text { - HR }=2.63 \text { ( } 95 \% \mathrm{CI} \text { I.57-4.04) adjusted for demographics } \\
\text { (urbanization, income) and comorbidities (hypertension, } \\
\text { dyslipidemia, diabetes, obesity) }\end{array}$ \\
\hline $\begin{array}{l}\text { Moran et al, }{ }^{48} \\
\text { Australia }\end{array}$ & $\begin{array}{l}\text { Cross-sectional } \\
\text { analysis of data from } \\
\text { a cohort based on } \\
\text { births (1973-1975) } \\
\text { at a large maternity } \\
\text { hospital }\end{array}$ & $\begin{array}{l}87 \text { with PCOS } \\
\text { and } 637 \text { without } \\
\text { PCOS }\end{array}$ & $\begin{array}{l}\text { Sleep disturbance } \\
\text { assessed using } \\
\text { modified Jenkins } \\
\text { questionnaire }\end{array}$ & $\begin{array}{l}\text { - Any sleep disturbances two times higher in women with } \\
\text { PCOS } \\
\text { - Difficulty falling asleep: OR = I.94 ( } 95 \% \mathrm{CI} \text { I.28-2.95), } \\
\text { attenuated but still significant after adjusting for } \mathrm{BMI} \text { and } \\
\text { depressive symptoms } \\
\text { - Difficulty maintaining sleep: OR = I.92 (95\% Cl } \\
\text { I.I2-3.3I), mediated by BMI and depressive symptoms } \\
\text { - PCOS not associated with early awakening or daytime } \\
\text { sleepiness }\end{array}$ \\
\hline
\end{tabular}

Abbreviations: BMI, body mass index; Cl, confidence interval; HR, hazard ratio; ICD-9, International Classification of Diseases, Ninth Revision; OR, odds ratio; OSA, obstructive sleep apnea; PCOS, polycystic ovary syndrome. 
not the latter. PCOS was not observed to be associated with unintended early morning waking or daytime sleepiness. ${ }^{48}$

\section{Clinic-based studies of sleep disturbances in women with PCOS}

Polysomnographic assessments of clinical samples of women with PCOS have been undertaken, with OSA the focus in the majority (summarized in Table 2). Interpretation of the findings of these studies should be tempered with understanding of the limitations of this literature: clinic-based samples of women with PCOS are likely to comprise women with the most severe symptoms; ${ }^{49}$ comparison groups are often convenience samples of women attending clinics for reasons other than PCOS; and sample sizes are often modest.

OSA is common in clinical samples of women with PCOS, affecting 17-75\%, substantially higher than in other women of similar age and BMI, and thus is not attributable to the tendency of women with PCOS to be obese. ${ }^{50-54}$ One study has shown that OSA is elevated in women who have $\mathrm{BMI}$ in the normal range along with PCOS. ${ }^{54}$ Women with PCOS have consistently been shown to have elevated AHI, regardless of OSA diagnosis. ${ }^{50,51,53-55}$ Few differences in other polysomnographic variables, such as sleep latency, sleep efficiency and waking after sleep onset, have been found. ${ }^{50,51,54,55}$

We have not systematically attended to studies of adolescents, given the difficulty in diagnosing PCOS at that stage of development and the likelihood that selection procedures (including factors involved in seeking an early diagnosis) contribute to inconsistent findings in polysomnographic studies. ${ }^{56-58}$ Of interest, however, one study demonstrated higher AHI and more OSA among obese girls with PCOS $(n=28)$ referred to a sleep clinic compared with a control group of girls $(n=28)$ matched for age and BMI, but no differences from a control group of boys $(n=28) .{ }^{59}$

Excessive daytime sleepiness (EDS) is a hallmark of sleep disturbance in men, but may not be as relevant to women ${ }^{60}$ who are more likely to report low mood or irritability or morning headaches following poor sleep. ${ }^{48,61}$ Nevertheless, EDS in women with PCOS has been investigated, ${ }^{50,51,54,55}$ usually using the Epworth Sleepiness Scale..$^{50,51,55}$ Predominantly, the clinical studies have shown PCOS to be associated with EDS, often in the absence of OSA. For example, in one study

Table 2 Summary of clinic-based studies of sleep disturbances and PCOS in women

\begin{tabular}{|c|c|c|c|c|}
\hline Study, country & $\begin{array}{l}\text { Study } \\
\text { design }\end{array}$ & Study groups & Outcomes of interest & Key results \\
\hline Fogel et al, ${ }^{50}$ USA & $\begin{array}{l}\text { Cross- } \\
\text { sectional, } \\
\text { PCOS and } \\
\text { comparison } \\
\text { group }\end{array}$ & $\begin{array}{l}18 \text { with PCOS, } \\
\text { all obese; and } 18 \\
\text { without PCOS } \\
\text { matched for age and } \\
\text { weight }\end{array}$ & $\begin{array}{l}\text { AHI, AHI (REM sleep), } \\
\text { OSA (AHI >5 with EDS), } \\
\text { ESS, sleep onset latency, } \\
\text { sleep efficiency, \% stages } 3 \\
\text { and } 4 \text { and \% REM sleep }\end{array}$ & 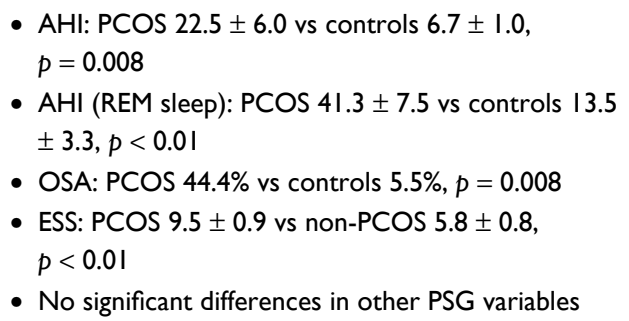 \\
\hline $\begin{array}{l}\text { Franik et al, }{ }^{62} \\
\text { Poland }\end{array}$ & $\begin{array}{l}\text { Cross- } \\
\text { sectional, } \\
\text { PCOS and } \\
\text { comparison } \\
\text { group }\end{array}$ & $\begin{array}{l}95 \text { with PCOS and } 95 \\
\text { without PCOS }\end{array}$ & AIS, ISI, ESS and PSQI & $\begin{array}{l}\text { - Clinically significant insomnia was higher in PCOS } \\
\text { o AIS }-12.6 \% \text { vs } 3.2 \%, p=0.0 \mathrm{I} \\
\text { o ISI }-10.5 \% \text { vs } I .1 \%, p=0.004 \\
\text { - No significant difference in ESS or PSQI }\end{array}$ \\
\hline Gopal et al, ${ }^{87}$ USA & $\begin{array}{l}\text { Cross- } \\
\text { sectional, } \\
\text { PCOS and } \\
\text { comparison } \\
\text { group }\end{array}$ & $\begin{array}{l}23 \text { with PCOS, all } \\
\text { premenopausal and } \\
\text { obese; and literature- } \\
\text { based historical } \\
\text { controls }\end{array}$ & $\begin{array}{l}\text { Snoring, RDI, OSA (RDI } \\
\geq 5 \text { ) and other variables (e.g. } \\
\text { arterial oxygen saturation) }\end{array}$ & $\begin{array}{l}\text { - } 16 / 23(69.6 \%) \text { met the criteria for OSA } \\
\text { - } 5 / 23 \text { required CPAP } \\
\text { - No correlation was found between degree of } \\
\text { obesity and severity of OSA } \\
\text { - No results reported for other variables }\end{array}$ \\
\hline $\begin{array}{l}\text { Mokhlesi et al, }{ }^{86} \\
\text { USA }\end{array}$ & $\begin{array}{l}\text { Cross- } \\
\text { sectional, } \\
\text { PCOS and } \\
\text { comparison } \\
\text { group }\end{array}$ & $\begin{array}{l}17 \text { with PCOS, all } \\
\text { nonobese; } 27 \text { with } \\
\text { PCOS, all obese; } \\
26 \text { without PCOS, } \\
\text { all nonobese; and } 8 \\
\text { without PCOS, all } \\
\text { obese }\end{array}$ & $\begin{array}{l}\text { Berlin questionnaire for } \\
\text { assessment of OSA risk }\end{array}$ & $\begin{array}{l}\text { - Women with PCOS had higher prevalence of high- } \\
\text { risk OSA }(47 \% \text { vs } 15 \%, \mathrm{p}<0.01) \\
\text { - None of the nonobese PCOS and nonobese control } \\
\text { women screened positive for OSA } \\
\text { - Obese PCOS vs obese controls had similar } \\
\text { prevalence of OSA } \\
\text { - BMI was only independent predictors of OSA }\end{array}$ \\
\hline
\end{tabular}

(Continued) 
Table 2 (Continued)

\begin{tabular}{|c|c|c|c|c|}
\hline Study, country & $\begin{array}{l}\text { Study } \\
\text { design }\end{array}$ & Study groups & Outcomes of interest & Key results \\
\hline Suri et al,,$^{51}$ India & $\begin{array}{l}\text { Cross- } \\
\text { sectional, } \\
\text { PCOS and } \\
\text { comparison } \\
\text { group }\end{array}$ & $\begin{array}{l}50 \text { with PCOS, all } \\
\text { untreated; and } 16 \\
\text { without PCOS, } \\
\text { matched for age, who } \\
\text { reported snoring }\end{array}$ & $\begin{array}{l}\text { RDI, SDB (RDI } \geq 5 \text { with } \\
\text { symptoms, RDI }>15 \\
\text { without symptoms), sleep } \\
\text { onset, TST, WASO, REM } \\
\text { sleep (minutes), NREM } \\
\text { sleep (minutes), sleep } \\
\text { efficiency, ESS and RERA }\end{array}$ & $\begin{array}{l}\text { - SDB: OR }=46.5 \text { ( } 95 \% \mathrm{Cl} \text { I4.6-I48.4), no longer } \\
\text { significant after adjusting for BMI and WC } \\
\text { - Higher RDI in PCOS with SDB }(22.5) \text { compared to } \\
\text { controls with SDB }(9.0), p=0.0 \text { I } \\
\text { - WASO: PCOS } 55.4 \pm 57.9 \text { vs non-PCOS } 30.5 \pm \\
\text { 26.4, } p=0.025 \\
\text { - ESS: PCOS I } 2.5 \pm 3.2 \text { vs non-PCOS } 9.32 \pm 1.7 \\
\text { P< } 0.00 \text { I } \\
\text { - No other significant differences in PSG variables }\end{array}$ \\
\hline \multirow[t]{3}{*}{ Tasali et al, ${ }^{52}$ USA } & $\begin{array}{l}\text { Cross- } \\
\text { sectional, } \\
\text { PCOS and } \\
\text { comparison }\end{array}$ & $\begin{array}{l}40 \text { with PCOS, } \\
\text { all nondiabetic, } \\
\text { completed } \\
\text { questionnaires }\end{array}$ & $\begin{array}{l}\text { ESS, PSQI and Berlin } \\
\text { questionnaire }\end{array}$ & $\begin{array}{l}\text { - } 62.5 \% \text { had poor sleep quality (PSQI }>5 \text { ) } \\
\text { - } 45 \% \text { had chronic daytime sleepiness (ESS score } \geq 10 \text { ) } \\
\text { - } 75 \% \text { had high risk of OSA by Berlin questionnaire }\end{array}$ \\
\hline & group & $\begin{array}{l}8 \text { with PCOS, } \\
\text { referred for PSG; } \\
\text { and } 8 \text { without PCOS, } \\
\text { matched for age, } \\
\text { nonobese }\end{array}$ & $\begin{array}{l}\text { Sleep efficiency, sleep } \\
\text { latency, TST, TWT, REM } \\
\text { sleep (minutes) and NREM } \\
\text { sleep (minutes) }\end{array}$ & $\begin{array}{l}\text { Measures of sleep efficiency in PCOS vs controls } \\
\text { - PCOS women had significantly lower sleep } \\
\text { efficiency and REM and NREM sleep compared to } \\
\text { controls } \\
\text { - PCOS women had significantly higher sleep latency, } \\
\text { TWT and TST compared to controls }\end{array}$ \\
\hline & & & $\begin{array}{l}\text { Severity of SDB measured } \\
\text { using AHI, MAI and ODI } \\
\text { during total, REM and } \\
\text { NREM sleep and minimum } \\
\text { oxygen saturation }\end{array}$ & $\begin{array}{l}\text { Measures of SDB severity in PCOS women } \\
\text { - AHI total (mean } \pm \mathrm{SE})=7.0 \pm 1.2 \\
\text { - } \mathrm{MAI} \text { total }(\text { mean } \pm \mathrm{SE})=17.6 \pm 1.8 \\
\text { - ODI total (mean } \pm \mathrm{SE})=10.8 \pm 2.2 \\
\text { - Minimum oxygen saturation }(\%)=80.6 \pm 1.6 \\
\text { - All values were higher during REM than NREM sleep }\end{array}$ \\
\hline Tasali et al, ${ }^{53}$ USA & $\begin{array}{l}\text { Cross- } \\
\text { sectional, } \\
\text { PCOS and } \\
\text { comparison } \\
\text { group }\end{array}$ & $\begin{array}{l}52 \text { with PCOS; and } \\
21 \text { without PCOS, } \\
\text { matched for age and } \\
\text { BMI }\end{array}$ & $\begin{array}{l}\text { AHI, OSA }(\mathrm{AHI}>5), \mathrm{TST} \\
\text { MAI and minimum oxygen } \\
\text { saturation }\end{array}$ & $\begin{array}{l}\text { - OSA: adjusted OR }=7 . I \text { ( } 95 \% \mathrm{Cl} \text { I.7-45.7), adjusted } \\
\text { for age, BMI and ethnicity } \\
\text { - Presence of OSA associated with significantly higher } \\
\text { MAI and minimum oxygen saturation among PCOS } \\
\text { group. Data not presented for four control women } \\
\text { with OSA } \\
\text { - No significant difference in TST }\end{array}$ \\
\hline $\begin{array}{l}\text { Vgontzas et al, }{ }^{54} \\
\text { USA }\end{array}$ & $\begin{array}{l}\text { Cross- } \\
\text { sectional, } \\
\text { PCOS and } \\
\text { comparison } \\
\text { group }\end{array}$ & $\begin{array}{l}53 \text { with PCOS, all } \\
\text { premenopausal; and } \\
452 \text { without PCOS }\end{array}$ & $\begin{array}{l}\text { Sleep apnea (AHI } \geq 10 \\
\text { with clinical symptoms), } \\
\text { upper airway resistance } \\
\text { syndrome, SDB, EDS, sleep } \\
\text { latency (minutes), WASO, } \\
\text { total wake time, \% sleep } \\
\text { time, \% stage I, \% stage } 2 \text {, } \\
\% \text { SWS and \% REM sleep }\end{array}$ & 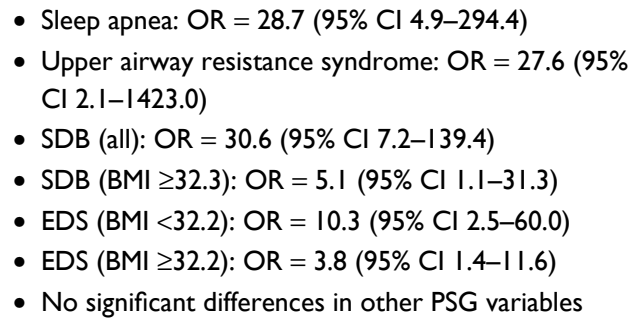 \\
\hline $\begin{array}{l}\text { Yang et al, }{ }^{55} \\
\text { Taiwan }\end{array}$ & $\begin{array}{l}\text { Cross- } \\
\text { sectional, } \\
\text { PCOS and } \\
\text { comparison } \\
\text { group }\end{array}$ & $\begin{array}{l}\text { I } 8 \text { with PCOS, } \\
\text { all nonobese and } \\
\text { untreated; } 10 \text { without } \\
\text { PCOS, matched for } \\
\text { age and BMI }\end{array}$ & $\begin{array}{l}\text { AHI (total, NREM sleep, } \\
\text { REM sleep), ARI (total, } \\
\text { NREM sleep, REM sleep, } \\
\text { spontaneous, PLM-related), } \\
\text { PLM, ESS, sleep efficiency, } \\
\text { sleep latency, \% REM sleep } \\
\text { and REM sleep latency }\end{array}$ & $\begin{array}{l}\text { - Mean total AHI: PCOS } 0.79 \pm 0.2 \mathrm{I} \text { vs non-PCOS } \\
0.29 \pm 0.09, p=0.04 \mathrm{I} \\
\text { - Mean AHI (NREM sleep): PCOS } 0.57 \pm 0.19 \text { vs non- } \\
\text { PCOS } 0.03 \pm 0.03, p=0.014 \\
\text { - No significant differences in other PSG variables } \\
\text { - None of the women in the study had AHI }>5\end{array}$ \\
\hline
\end{tabular}

Note: Sleep efficiency $=$ TST/TIB.

Abbreviations: AHI, apnea-hypopnea index; AIS, Athens Insomnia Scale; ARI, arousal index; BMI, body mass index; Cl, confidence interval; CPAP, continuous positive airway pressure; EDS, excessive daytime sleepiness; ESS, Epworth Sleepiness Scale; ISI, Insomnia Severity Index; MAI, microarousal index; NREM, non-rapid eye movement; ODI, oxygen desaturation index; OR, odds ratio; OSA, obstructive sleep apnea; PCOS, polycystic ovary syndrome; PLM, periodic limb movement; PSG, polysomnography; PSQI, Pittsburgh Sleep Quality Index; RDI, respiratory distress index; REM, rapid eye movement; RERA, respiratory effort-related arousal; SDB, sleep-disordered breathing; SE, standard error; SWS, slow-wave sleep; TIB, time in bed (minutes); TST, total sleep time (minutes); TWT, total wake time (minutes); WASO, wake after sleep onset (minutes); WC, waist circumference. 
$80 \%$ of women with PCOS $(n=53)$ complained of EDS but only $17 \%$ were diagnosed with OSA. ${ }^{54}$

Insomnia in women with PCOS has received very little attention. Among a clinical sample of Polish women with PCOS ( $\mathrm{n}=95), 13 \%$ had insomnia according to the Athens Insomnia Scale and 10\% according to the Insomnia Severity Index (ISI), with corresponding proportions among controls $(n=130)$ of $3 \%$ and $1 \%$, respectively. ${ }^{62}$

\section{How pathophysiology of PCOS is linked to sleep disturbances}

Since PCOS is characterized by metabolic disturbances, and as the endocrine system has an important role in governing the sleep-wake cycle, it is likely that PCOS interferes with arousal and sleep or that there is a more complex interrelationship.

The sleep-wake cycle in humans is driven by the interaction between two processes, Process $\mathrm{S}$, which is sleep promoting, and Process C, which promotes wakefulness. ${ }^{63}$ Process $S$ represents the homeostatic need for sleep and accumulates over the time spent awake. Process $\mathrm{C}$ is regulated by the circadian system and ensures that sleep and wakefulness coincide with environmental light-dark stimuli. ${ }^{64}$ The circadian system is coordinated centrally by the suprachiasmatic nucleus in the hypothalamus and is synchronized with environmental stimuli. ${ }^{65}$ The suprachiasmatic nucleus relays circadian information to other areas of the brain, such as the pituitary and pineal pineal glands, and to peripheral tissues via the regulation of clock-gene expression and neuroendocrine signaling. ${ }^{66}$

Melatonin and cortisol play important roles in regulating sleep and wakefulness. Melatonin, secreted by the pineal gland, is increased at night and decreased during the day, thus communicating light-dark information. ${ }^{64,67}$ Cortisol, which is secreted from the adrenal cortex and regulated by the HPA axis, also follows a circadian pattern, steadily increasing during sleep and peaking in the morning. ${ }^{67,68}$

As illustrated in Figure 2, there are several pathways through which PCOS and sleep disturbances may be associated. The pathways outlined here have been identified based on the endocrine profiles of women with PCOS, the unique stressors they experience, and related psychological and behavioral factors.

\section{Obesity}

Obesity is common in women with PCOS and exacerbates the metabolic stress that we and others view as central to pathogenesis of the syndrome. ${ }^{25}$ In a meta-analysis of mainly clinic-based samples ( $\mathrm{n}=35$ studies), ${ }^{69} 49 \%$ of women with PCOS were classified as obese (95\% CI 42-55\%) and 54\% had central adiposity (95\% CI 43-62\%). The proportions were around twofold higher than among comparison groups (obesity: relative risk $[\mathrm{RR}]=2.8,95 \%$ CI 1.9-4.1; central adiposity: $\mathrm{RR}=1.7,95 \%$ CI 1.3-2.3). These proportions should not be interpreted as prevalence estimates for all women with PCOS because obesity has been shown to be more common (and more extreme) in clinical samples than in community-based studies. ${ }^{49}$ For example, in the Australian Longitudinal Study on Women's Health (overall $n=9145$ ), at wave 4, 478 women reported having received a diagnosis of PCOS and, on average, had moderately higher BMI (mean difference $2.5 \mathrm{~kg} / \mathrm{m}^{2}, 95 \%$ CI 1.9-3.1) and moderately greater longitudinal weight gain over a 10-year period (mean difference $2.6 \mathrm{~kg} \mathrm{~kg} / \mathrm{m}^{2}, 95 \% \mathrm{CI}$ 1.2-4.0) compared to their peers. ${ }^{70}$

Variation in BMI among women with PCOS appears to be related to factors such as age and ethnicity and possibly to severity of the syndrome. ${ }^{69}$ It is not clear why women with PCOS are predisposed to obesity, nor whether it reflects physiology or psychology. Some literature suggests that appetite and satiety are altered in PCOS, with affected women reporting higher postprandial hunger and lower satiety after a test meal compared to other women. ${ }^{71}$ Underlying postprandial suppression of gut hormones such as ghrelin, cholecystokinin, glucagon-like peptide 1 and peptide YY may occur in PCOS. ${ }^{71-74}$ Alternatively or additionally, obesity may reflect abnormalities in energy expenditure as women with PCOS have been found to have reduced resting metabolic rate (1659 $\mathrm{kJ} /$ day $)^{75}$ and reduced thermic effect of food $(42 \mathrm{~kJ} / \mathrm{meal}$, equivalent to weight gain of $1.9 \mathrm{~kg} / \mathrm{year}) .{ }^{76}$ Psychological factors are consistent correlates of poor weight management $;{ }^{77}$ as will be described presently, women with PCOS have relatively more anxiety and depression, and relatively poor self-esteem, body image and quality of life (QoL), compared to their peers. ${ }^{78}$

Obesity is one of the strongest risk factors for OSA, ${ }^{79}$ attributable to anatomical changes of the upper airways and thoracic region. ${ }^{80}$ Longitudinal studies of men and women demonstrate that a $10 \%$ increase in body weight predicts a sixfold increase in risk of developing moderate-to-severe sleep-disordered breathing. ${ }^{81}$ When obesity is severe (BMI $>40 \mathrm{~kg} / \mathrm{m}^{2}$ ), the prevalence of OSA in men and women is as great as $92 \% .{ }^{82}$

There is evidence that obesity contributes to sleep disturbances beyond OSA. ${ }^{83}$ Several studies have shown that obesity is associated with objectively assessed daytime sleepiness and subjective reports of fatigue, independently of OSA ${ }^{84,85}$ Vgontzas et $\mathrm{al}^{83}$ have proposed two possible mechanisms through which obesity produces these sleep disturbances. In one pathway, shorter sleep duration and subjective fatigue in obese 
individuals is related to psychological distress and upregulation of the HPA axis. In the second pathway, in which sleep duration is not altered, metabolic parameters such as insulin resistance as well as lack of physical activity are invoked, with normal- or downregulation of the HPA axis. Both pathways are proposed to be associated with hypercytokinemia. ${ }^{83}$

There is some evidence that obesity directly contributes to OSA among women with PCOS, although, as highlighted previously, it does not fully account for findings from community- and clinic-based studies. For example, high BMI in women with PCOS $(n=53)$ has been associated with elevated risk of OSA and daytime sleepiness. ${ }^{54}$ In a study of women with $(n=44)$ and without $(n=34)$ PCOS, obesity was the strongest predictor of sleep apnea risk (as measured by the Berlin questionnaire) ${ }^{86}$ in contrast to another study of obese women with PCOS $(n=23)$, among whom there was no relationship between the degree of obesity and sleep apnea severity (as per AHI). ${ }^{87}$

On balance, the evidence supports contributions to sleep disorders both of PCOS and obesity. From the perspective of stress, the former is metabolic while the latter is oxidative, which might aggravate sleep harmonically, ${ }^{25}$ but studies that examine this are lacking.

\section{Hyperandrogenemia}

The prevalence of OSA differs by sex, with obese women having lower risk compared to males of similar BMI. ${ }^{88}$ Men and women often have different clinical presentations for OSA. For example, when matched for age, BMI, AHI and EDS score, women were less likely than men to present with witnessed apnea but more likely to report insomnia. ${ }^{89}$ Differences between men and women may be due to differences in the anatomy of the upper airway, sex hormones and/or central adiposity. ${ }^{90,91}$

Women with PCOS commonly have increased testosterone (free and bound) and androstenedione, and hyperandrogenemia is a diagnostic criterion. Excess androgen is known to induce changes in body composition, including increased central adiposity. In women with PCOS, serum androgen levels are positively correlated with waist-hip ratio, independent of obesity. ${ }^{92}$ Androgen-induced changes to central adiposity, rather than increased weight overall, may contribute to OSA in these women.

This proposition is supported by work showing that among obese women with PCOS $(n=18)$, the severity of OSA was correlated with both the degree of androgen excess and waist-hip ratio. ${ }^{50}$ Similarly, among nonobese women with $(n=18)$ and without $(n=10)$ PCOS, who did not have
OSA, AHI during non-rapid eye movement (NREM) sleep was correlated with total testosterone. ${ }^{55}$ An inconsistent finding has been reported for a group of women with PCOS $(n=44)$ in whom risk of OSA was determined by the Berlin questionnaire. ${ }^{86}$

Few studies have investigated the potential role of hyperandrogenemia in other forms of sleep disturbance in women. Mixed findings about androgens and sleep architecture have been reported from polysomnographic studies of adolescent girls with PCOS. ${ }^{56,93}$

\section{Insulin resistance}

There is considerable evidence for a relationship between sleep disturbances and insulin resistance, with numerous studies demonstrating that sleep restriction and/or sleep disorders can exacerbate insulin resistance. ${ }^{94-96}$ Insulin resistance may also have a role in the development of sleep disturbances. For example, in a cross-sectional study of risk factors for EDS $(n=1741)$ undertaken in the US, diabetes (fasting glucose $>126 \mathrm{mg} / \mathrm{dL}$ ) was strongly associated with EDS. ${ }^{84}$ Similarly, in a small study of men with OSA, those with $\operatorname{EDS}(n=22)$ had higher plasma insulin levels and insulin resistance compared with those without EDS $(n=22)$ when matched for age, BMI, and AHI. ${ }^{97}$ A prospective study of incident OSA in a population-based sample of French men and women $(n=3565)$ also demonstrated that fasting hyperinsulinemia predicted development of OSA, independently of BMI. ${ }^{98}$

The mechanisms by which insulin resistance may lead to OSA or EDS are unknown. Evidence from animal and human studies has demonstrated that insulin increases sympathetic outflow, ${ }^{99,100}$ which may in turn affect sleep architecture and the risk of sleep-disordered breathing and daytime sleepiness.

In a polysomnographic study of women with $(n=53)$ and without ( $\mathrm{n}=452$ ) PCOS, Vgontzas et al found that insulin resistance was the strongest risk factor for sleep apnea, before and after controlling for age, BMI, and free and total testosterone levels. ${ }^{54}$ Similar findings were reported in another study of women with PCOS ( $\mathrm{n}=40)$, with higher fasting insulin levels observed among those with elevated risk of OSA (as per Berlin questionnaire). ${ }^{52}$

If insulin resistance causes sleep disturbances, then treatment with insulin sensitizers should be mitigating. Adolescent girls with PCOS who received metformin treatment reported reduced sleep disturbances and daytime sleepiness, but it is not possible to distinguish between effects of improved insulin resistance and the concomitant reductions in BMI and hyperandrogenemia. ${ }^{101}$ In a recent pilot for a 
randomized placebo-controlled trial, nondiabetic individuals with insulin resistance and OSA $(n=45)$ were allocated to receive either pioglitazone or placebo. Pioglitazone produced no improvement in OSA symptoms or other measures of sleep quality, despite significant improvements in insulin sensitivity. ${ }^{102}$ Thus, there is insufficient evidence to draw conclusions about this matter, and we recommend further research.

\section{Cortisol}

In a recent longitudinal study of obese girls aged 13-16 years with $(n=20)$ and without PCOS $(n=20)$, the role of the steroid metabolome was investigated. No difference in morning cortisol concentration was found between the two groups, although levels were twice as high as those reported in studies of girls of normal weight. ${ }^{103}$ Furthermore, weight loss was associated with a decrease in cortisol whether or not the girls had PCOS. Together, this suggests that the adrenal stimulation was attributable to obesity rather than to PCOS.

Findings concerning women with PCOS are somewhat contradictory. In one study $(\mathrm{n}=21$ with PCOS, 11 overweight/obese; $n=10$ without PCOS, none overweight/obese), 24-hour cortisol profiles were obtained. While there was no difference in mean 24-hour cortisol levels overall, women with PCOS had lower night-time cortisol levels compared to controls, and this was most pronounced for the women with PCOS who were not overweight/obese. ${ }^{104}$ In another study, evening, but not morning, plasma cortisol levels were higher in women with PCOS $(n=40)$ compared to women of similar age and BMI without PCOS $(n=55) .{ }^{105}$ It is possible that elevated cortisol levels among women with PCOS reflect high $\mathrm{BMI}$, as one study showed that concentration and profiles of cortisol excretion were similar for obese women with $(\mathrm{n}=15)$ and without $(\mathrm{n}=15)$ PCOS. ${ }^{106}$

Complete HPA function in women with PCOS has not been described. Any changes - whether due to PCOS or associated obesity - are relevant, as dysfunction of the HPA axis at any level impacts on sleep, including increased sleep fragmentation, decreased slow wave sleep, and shortened sleep time. ${ }^{107}$

There is evidence that women with PCOS have a heightened physiological response to emotional stress. When exposed to an experimental stressor, women with PCOS $(n=32)$ had higher levels of adrenocorticotropic hormone immediately and 15 minutes post-stress, and higher serum cortisol level 15 minutes post-stress, compared to women without PCOS $(n=32)$, matched for age and BMI. This was despite the emotional response (state anxiety) reported by the two groups being similar. ${ }^{108}$
Sleep deprivation is itself a stressor and is associated with elevated cortisol levels. ${ }^{109}$ It is therefore possible that a bidirectional relationship exists between stress-related hyperactivity of the HPA axis and sleep disturbances in women with PCOS. ${ }^{110}$

\section{Melatonin}

A study of melatonin secretion over 24 hours in women with PCOS has not been undertaken. Melatonin from a single blood sample taken between midnight and 4 am was higher among women with PCOS $(\mathrm{n}=50)$ compared to controls $(\mathrm{n}=50) .{ }^{111}$ Two studies have demonstrated elevated 24 -hour urinary 6-sulphatoxymelatonin (the primary metabolite of melatonin) in women with PCOS ( $\mathrm{n}=22$ in the first and $\mathrm{n}=24$ in the second study) compared to controls $(\mathrm{n}=35$ and $\mathrm{n}=26$, respectively). ${ }^{112,113}$

However, the changes in melatonin described in women with PCOS are unlikely to result in the profound sleep disturbances that have been reported in this subpopulation, particularly given 6-sulphatoxymelatonin was not found to be correlated with sleep efficiency. ${ }^{113}$ A strong correlation between melatonin obtained from a single blood sample (as above) and testosterone was found in women with PCOS, ${ }^{111}$ and melatonin was reduced after hyperandrogenemia was attenuated by cyproterone acetate-ethinyl estradiol treatment. ${ }^{114}$ This suggests that elevated melatonin levels described in women with PCOS may be a result of androgen excess. Conversely, chronic administration of melatonin to women with PCOS ( $2 \mathrm{mg}$ per day for six months) significantly decreased testosterone levels and reduced menstrual irregularities, ${ }^{115}$ suggesting that supraphysiological levels of melatonin can reduce androgen levels.

\section{Psychosocial aspects of PCOS and association with sleep}

A number of psychosocial aspects of PCOS are likely to contribute to sleep disorders and disturbances in affected women. These are summarized in Figure 4.

\section{Mental health profiles of women with PCOS}

Anxiety and depression are well recognized to be associated with sleep disorders. ${ }^{116-118}$ A systematic review of nine longitudinal studies found suggestive, though not definitive, evidence of a bidirectional relationship. ${ }^{119}$ A recent study of young women $(n=171)$ followed over two weeks found reciprocal dynamics between anhedonic depression and disrupted sleep to be especially potent. ${ }^{120}$ 


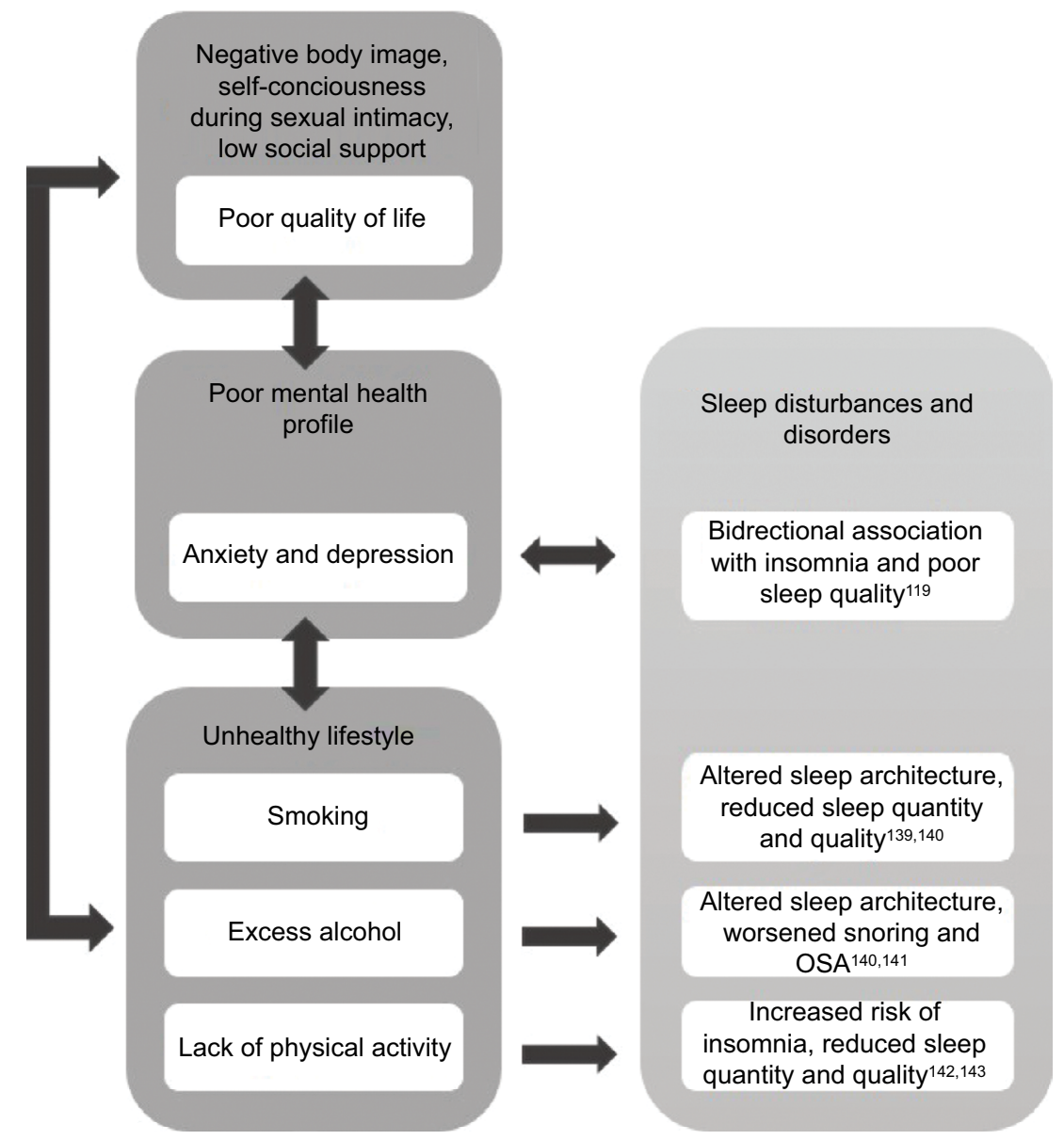

Figure 4 Summary of psychosocial and behavioral factors that are common among women with PCOS and their potential contribution to sleep disturbances and disorders. Abbreviations: OSA, obstructive sleep apnea; PCOS, polycystic ovary syndrome.

Anxiety and depression are elevated in women with PCOS, with consistent evidence presented in several systematic reviews with meta-analysis. ${ }^{121-125}$ In our communitybased sample, among women with PCOS (the majority of whom had not previously been diagnosed), $50 \%$ had symptoms consistent with clinical depression (Center for Epidemiologic Studies Depression Scale) compared with $30 \%$ of their peers. ${ }^{48}$

In one of the above systematic reviews, ${ }^{125}$ clinical symptoms, including hirsutism, obesity, and infertility, were shown to contribute to higher emotional distress in women with PCOS, but did not fully account for the disparity. Elevated androgens have been associated with negative affect and depressive symptoms in women with PCOS, ${ }^{78,126}$ but the relationship between androgens and mood disorders in women remains controversial. ${ }^{124,127}$ As discussed, women with PCOS may have hyperresponsivity of the HPA axis, which is associated with impaired mental health, including depression. $^{128}$
In the community-based cohort of Australian women that we undertook, as mentioned, difficulty falling asleep and difficulty maintaining sleep were twice as common in women with PCOS compared to peers of similar age. ${ }^{48}$ Depressive symptoms mediated both associations, but to varying degrees.

In a clinical sample of women with PCOS $(n=114)$, those with a history of depression had a threefold increase in disturbed sleep (as per the Patient Health Questionnaire). ${ }^{129}$ In another study, women with $(\mathrm{n}=30)$ and without PCOS $(n=30)$, matched for age and BMI, were recruited by advertisement in a Swedish community. ${ }^{130}$ Symptoms of anxiety and depression were self-reported (using subscales of the Comprehensive Psychopathological Rating Scale for Affective Syndromes). Over $60 \%$ of women with PCOS had anxiety symptoms above a cut-point corresponding to clinical relevance, compared to $13 \%$ of controls, with the specific symptom of reduced sleep prominent.

As with anxiety and depression, it is likely that a bidirectional relationship exists between sleep and 
QoL. ${ }^{131}$ This may be especially so in people with medical conditions. $^{132}$

QoL for girls and women with PCOS appears to be poorer than for their peers, although less is known about this than about specific conditions such as depression and anxiety. A systematic review and meta-analysis of five studies showed that women with PCOS had lower scores than their counterparts on all domains assessed by the Short Form-36 Health Survey, including physical and social function. ${ }^{133}$ A recent systematic review ${ }^{134}$ of QoL in adolescents and young women with PCOS identified nine studies that were too diverse in approach for meta-analysis to be performed. However, all studies reported a negative association between PCOS and QoL, with body weight issues conspicuous.

Distressing symptoms of PCOS are likely to contribute to poor QoL. In women more broadly, a systematic review with meta-analysis has demonstrated the profound impact of infertility on QoL. ${ }^{135}$ Other stressors experienced by women with PCOS - that have received less attention - may contribute, including negative body image, poor self-esteem, poor sexual relations, reduced social support and low social engagement. ${ }^{136-138}$

\section{Lifestyle and health behaviors}

Lifestyle factors and health behaviors, including smoking, consumption of alcohol and lack of physical activity, can contribute to impaired sleep. Tobacco smoking has been associated with altered sleep architecture, short sleep duration and poor-quality sleep, based on both self-reports and polysomnography. ${ }^{139,140}$ In nonalcoholics, the effect of alcohol consumption on sleep varies during the night, at first decreasing sleep latency and increasing the quality and quantity of NREM sleep, then as alcohol is metabolized, reducing NREM and fragmenting sleep. ${ }^{140,141}$ Alcohol is also associated with exacerbation of snoring and OSA. ${ }^{140}$ Physical inactivity has been associated with reduced self-reported hours of sleep ${ }^{142}$ and increased risk of clinically diagnosed insomnia. ${ }^{143}$ Furthermore, there is evidence that increased physical activity improves sleep quality. ${ }^{144,145}$

There is some evidence that lifestyles and behaviors of women with PCOS are less healthy than those of other women of similar age and socioeconomic status. For example, in a case series of women with PCOS presenting at a reproductive health clinic, around half smoked cigarettes, substantially more than expected based on their demographic profile. ${ }^{146}$ Consistent with this, in the US 2002 National Health Interview Survey, women who reported menstrual-related problems were shown to be more likely than others to smoke and drink heavily. ${ }^{147}$

Women with PCOS are less physically active than other women and may have difficulty in sustaining engagement in physical activity over the long term. ${ }^{148}$ When interventions to improve physical activity among women with PCOS have been trialed, attrition rates have been high. ${ }^{149}$ Barriers contributing to low physical activity in women with PCOS include lack of confidence in the ability to maintain activity, fear of injury and physical limitations. ${ }^{148}$ It is also possible that there are physiological reasons for impaired exercise capacity in women with PCOS. For example, it has been shown that sedentary normal-weight women with PCOS $(n=14)$ have impaired cardiorespiratory capacity (maximal oxygen consumption and submaximal ventilatory thresholds) compared to age- and BMI-matched sedentary women without PCOS $(n=14) .{ }^{150}$

\section{Long-term cardiometabolic consequences of sleep disturbances in PCOS}

There are few long-term studies of women with PCOS, with information especially lacking after menopause. However, available evidence suggests that women with PCOS may have relatively early onset of type 2 diabetes and other cardiometabolic disorders. This is not accounted for by the higher prevalence of obesity among women with PCOS, as highlighted in the studies described here. Drawing on wider literature, it is possible that sleep disorders may contribute to deterioration in the heath of women with PCOS, although this has not been studied directly.

Detailed cardiovascular profiles of around 1000 women were obtained across 20 years in the CARDIA (Coronary Artery Risk Development in Young Adults) study undertaken in the US, commencing when participants were aged 18-30 years. Information on PCOS symptoms obtained 16 years from baseline was combined with androgen data from year 2 to classify women as having PCOS or not. Using data from year 5, women with PCOS $(n=42)$ had higher left ventricular mass index and larger left arterial diameter. ${ }^{151}$ By year 16 , when women were aged 34-46 years, PCOS was associated with a twofold increase in incident diabetes (with almost a quarter of women with PCOS affected) and a twofold increase in dyslipidemia. Among women with normal BMI, those with PCOS $(n=31)$ had three times the rate of diabetes compared to those without PCOS. ${ }^{152}$ At year 20, women with PCOS $(n=55)$ had increased coronary artery calcification and intima-media thickness. ${ }^{153}$ 
Australian hospital admission data from 1980 to 2011 have been used to compare 2566 women with a recorded diagnosis of PCOS to 25,660 age-matched women (identified using the electoral roll); most women in this study were aged under 40 years. Women with a diagnosis of PCOS were two to three times more likely to be hospitalized for adult-onset diabetes, hypertensive disorders, ischemic heart disease and cerebrovascular disease compared to women without PCOS. These findings remained statistically significant after adjusting for obesity. ${ }^{154}$

In a retrospective cohort study, women with PCOS $(n=319)$ identified through hospital records were compared with age-matched women $(n=1060)$ identified through general practice records. After an average follow-up of 31 years, when approximately $80 \%$ of women were postmenopausal, those with PCOS had elevated prevalence of diabetes, hypertension and high cholesterol. ${ }^{155}$ Another study with a small sample size and substantial losses to follow-up over 21 years found more hypertension and higher triglycerides in women with PCOS ( $n=25$ of 35) compared to women of similar age and BMI $(n=68$ of 120$) .{ }^{156}$

Turning to the wider literature, a recent meta-analysis of cohort studies showed that OSA was associated with increased risk of type 2 diabetes after adjustment for age, sex and BMI ( $R R=1.49,95 \%$ CI 1.27-1.75, eight studies, 63,647 participants). ${ }^{157}$ Other types of sleep disturbance were also associated with type 2 diabetes, notably - in view of our findings on women with $\mathrm{PCOS}^{48}$ - difficulty initiating sleep $(\mathrm{RR}=1.55,95 \% \mathrm{CI} 1.23-1.95)$ and difficulty maintaining sleep ( $R R=1.72,95 \%$ CI 1.45-2.05).

Sleep restriction has been demonstrated to result in increased food intake due to increased appetite, exceeding the energy amount needed to meet the requirements of extended wakefulness, and thereby resulting in weight gain. ${ }^{158-160}$ It has also been shown to decrease the ability to lose body fat with dietary restriction, ${ }^{158,161}$ and to alter glucose metabolism, with decreases in glucose clearance, insulin sensitivity and acute insulin response documented. ${ }^{158,162,163}$

OSA is likely to increase the risk of diabetes through intermittent hypoxia and arousals, which result in impaired glucose tolerance through increasing sympathetic nervous system activity, HPA axis dysregulation, altered cytokine release and oxidative stress. ${ }^{164-167}$ OSA is also independently associated with hypertension, premature atherosclerosis and arterial stiffness and an increased risk of future myocardial infarction, stroke and cardiovascular mortality. ${ }^{166,168,169}$ This may be due to the combination of sympathetic nervous system stimulation and endothelial dysfunction that result from OSA. ${ }^{170,171}$

In studies of short duration, insulin-glucose metabolism and lipids are worse in women with PCOS who have OSA than among women with PCOS but not OSA, independent of BMI. ${ }^{52,54,59,172} \mathrm{~A}$ link between sleep disturbances and poor long-term cardiometabolic health among women with PCOS remains speculative, as direct evidence is lacking.

\section{Management of sleep disturbances in PCOS}

Referral to a sleep specialist allows diagnosis of clinical conditions such as OSA and insomnia, and subsequent treatment. OSA is generally diagnosed using overnight polysomnography to generate AHI. ${ }^{40}$ Insomnia diagnosis ideally requires assessment by a clinical psychologist. ${ }^{173}$ However, many sleep medicine clinics do not currently have the resources necessary for adequate diagnosis, such as the ISI questionnaire, sleep diaries and measures of daytime fatigue without sleepiness. It important to recognize that OSA and insomnia are frequently comorbid, ${ }^{173}$ and also that women with PCOS may have other forms of sleep disturbance.

Weight loss is generally recommended for overweight and obese people with OSA, ${ }^{40}$ although recent research has indicated that weight loss may only decrease the severity of OSA in a minority of patients. ${ }^{174}$ As described above, weight loss may be particularly difficult to achieve in many women with PCOS due to hormonal abnormalities and other factors. Weight loss in women with PCOS would improve insulin sensitivity and symptom profiles, including fertility, so research is needed to understand the type and intensity of support required to achieve this. Avoidance of alcohol and sedative medications, which may predispose the upper airway to collapse, is also frequently recommended for OSA. ${ }^{40}$ Again, this poses a particular difficulty for women with PCOS in view of their anxiety and use of alcohol, possibly as a coping mechanism. ${ }^{175}$

In cases of mild OSA, oral appliances, commonly known as mandibular advancement splints, which are custom-made to increase upper airway size and reduce the likelihood of airway collapse during sleep, may be recommended ${ }^{40}$ However, efficacy and acceptability of oral appliances in women with PCOS is yet to be explored.

A small amount of research has been conducted in women with PCOS about the benefits of continuous positive airway pressure (CPAP) treatment, involving wearing a mask over the nose during sleep to maintain airway patency. CPAP has 
been shown to be a promising treatment for OSA in young obese women with PCOS, with improvements in insulin sensitivity, daytime diastolic blood pressure, and cardiac sympathovagal balance after eight weeks of treatment. ${ }^{176}$ These results indicate the need for a larger, well-designed randomized controlled trial to assess the clinically relevant effects of CPAP treatment on markers of future cardiovascular risk in women with PCOS. ${ }^{177}$

For the general OSA subpopulation (mostly men), there is now evidence from systematic reviews with meta-analysis that CPAP reduces blood pressure ${ }^{178}$ and endothelial dysfunction, which promote the development of atherosclerosis. ${ }^{179,180}$ Thus, CPAP could have a role in primary prevention of vascular disease, despite recent findings that CPAP is not effective in reducing coronary events in those with preexisting vascular disease. ${ }^{181}$ Systematic reviews with meta-analysis have also indicated that insulin resistance can be improved with CPAP use, thereby possibly reducing the risk of development of type 2 diabetes in nondiabetic and prediabetic individuals. ${ }^{18}$

Importantly for women with PCOS, a systematic review with meta-analysis has provided evidence that CPAP treatment reduces depressive symptoms. ${ }^{182}$ A subsequent large, randomized controlled trial of over 2000 individuals with moderate-to-severe OSA and coronary or cerebrovascular disease demonstrated that CPAP was effective in increasing QoL as well as decreasing symptoms of depression and anxiety. ${ }^{183}$

The American College of Physicians now recommends cognitive behavior therapy (CBT) as the most appropriate treatment for all adults with insomnia. ${ }^{184}$ This treatment is also recommended as a first-line treatment for insomnia by the British Association for Psychopharmacology. ${ }^{185}$ The efficacy of CBT in treating insomnia symptoms has been demonstrated in multiple systematic reviews with meta-analyses, ${ }^{186-189}$ but most sleep clinics do not have clinical psychologists available to provide this treatment. In view of the widespread mental health and other problems reported among women with PCOS, there is a good case for referral to a clinical psychologist who can assess and address problems holistically.

In recent years, trials have been undertaken to assess the efficacy of online delivery of CBT for insomnia, using highly structured internet programs as a means of overcoming the barriers to face-to-face delivery of treatment. ${ }^{190} \mathrm{~A}$ recent systematic review with meta-analysis of 15 randomized controlled trials of internet CBT for insomnia found evidence of clinically significant improvements in symptoms, of the order achieved in face-to-face CBT. ${ }^{190}$ Importantly, the ISI score of patients was found to be reduced overall by $21 \%,{ }^{190}$ and by $15 \%$ in a similar systematic review with meta-analysis. ${ }^{191}$ This option may appeal to women with
PCOS as cost-effective, but they should still be encouraged to consult a clinical psychologist or other professional support services for wider problems.

There are well-recognized hazards in using pharmacotherapy for the primary treatment of insomnia. Depending on the type of drug used, negative effects include carry-over daytime sedation, slowed reactions and memory impairment, as well as the potential for intensification of symptoms upon cessation of treatment. ${ }^{173}$ Pharmacotherapy is only recommended short term. ${ }^{192}$ This is particularly pertinent for women with PCOS whose insomnia and other sleep disturbances are unlikely to be short term and are related to underlying factors that need to be addressed directly.

Women who experience sleep disturbances, but do not meet the criteria for clinical diagnosis of a sleep disorder, may benefit from sleep hygiene approaches. This includes behavioral and environmental recommendations for promoting sleep. ${ }^{193}$ Avoidance of smoking and alcohol and regular physical activity are aspects of sleep hygiene that have already been described. Other recommendations include avoidance of caffeine, adhering to regular sleep and wake times and stress management. ${ }^{193}$ Stress management techniques, such as mindfulness, have been shown to reduce presleep arousal and worry, ${ }^{194}$ which may be beneficial for women with PCOS. Clinical anxiety requires psychological expertise, however.

As has been highlighted throughout this review, it is common for women with PCOS to experience symptoms that span multiple medical specialties. The management of sleep disturbances among women with PCOS should form part of an interdisciplinary model of care (summarized in Figure 5) with effective communication between care providers. ${ }^{195}$ It is important that interdisciplinary care is patient-centered ${ }^{195}$ and emphasizes a holistic approach to health and well-being.

\section{Conclusion}

There is mounting evidence for an association between PCOS and sleep disturbances that is complex and possibly bidirectional. This is not simply due to the tendency of women with PCOS to be obese, as associations are seen in PCOS women of normal weight and most associations are upheld after adjustment for BMI. This suggests poor sleep is part of the pathophysiology of PCOS. We view PCOS as a condition of severe metabolic stress that cascades into oxidative and emotional stress. We suggest that multidimensional treatment, including treatment to improve sleep, may improve metabolic function and could potentially prevent long-term cardiometabolic sequelae for these women.

We have identified some important gaps in the literature, with further research recommended. These include a need 


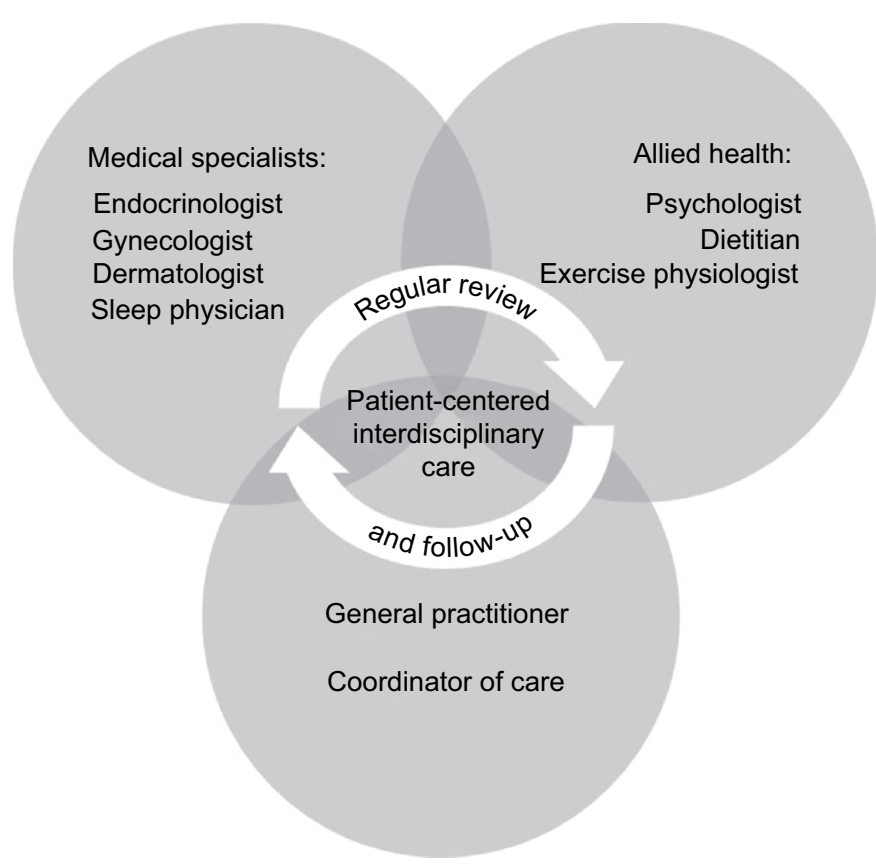

Figure 5 Model of interdisciplinary care recommended for management of sleep disturbances and disorders in women with PCOS.

Note: Teede HJ, Misso ML, Deeks AA, et al. Assessment and management of polycystic ovary syndrome: summary of an evidence-based guideline. Med J Aust. 20I I; 195 (6 Suppl):S65-SI I2. (C) Copyright 20II The Medical Journal of Australia - figure adapted and reproduced with permission. ${ }^{195}$

Abbreviation: PCOS, polycystic ovary syndrome.

to fully describe HPA function in women with PCOS, and for further trials of insulin sensitizers and interventions designed to overcome the specific difficulties that women with PCOS have in sustaining physical activity. The implications for sleep deserve specific attention as well as the possibility that bidirectional processes can be harnessed so that improved sleep reduces metabolic stress in women with PCOS.

\section{Acknowledgments}

The authors thank Stephanie Champion, Ph.D., and Alice Rumbold, Ph.D., for assistance with summarizing relevant literature. Dr JC Avery was supported by a fellowship from the Australian National Health and Medical Research Council (NHMRC) Centre for Research Excellence in Polycystic Ovary Syndrome. Prof RD McEvoy is the recipient of an NHMRC Practitioner Fellowship.

\section{Disclosure}

The authors report no conflicts of interest in this work.

\section{References}

1. Roe AH, Dokras A. The diagnosis of polycystic ovary syndrome in adolescents. Rev Obstet Gynecol. 2011;4(2):45-51.

2. Stein IF, Leventhal ML. Amenorrhea associated with bilateral polycystic ovaries. Am J Obstet Gynecol. 1935;29(2):181-191.

3. Diamanti-Kandarakis E, Dunaif A. Insulin resistance and the polycystic ovary syndrome revisited: an update on mechanisms and implications. Endocr Rev. 2012;33(6):981-1030.
4. El Hayek S, Bitar L, Hamdar LH, Mirza FG, Daoud G. Polycystic ovarian syndrome: an updated overview. Front Physiol. 2016;7:124.

5. Javed A, Kumar S, Simmons PS, Lteif AN. Phenotypic characterization of polycystic ovary syndrome in adolescents based on menstrual irregularity. Horm Res Paediatr. 2015;84(4):223-230.

6. Housman E, Reynolds RV. Polycystic ovary syndrome: a review for dermatologists: Part I. Diagnosis and manifestations. J Am Acad Dermatol. 2014;71(5):847.e841-847.e810.

7. Sivayoganathan D, Maruthini D, Glanville JM, Balen AH. Full investigation of patients with polycystic ovary syndrome (PCOS) presenting to four different clinical specialties reveals significant differences and undiagnosed morbidity. Hum Fertil. 2011;14(4):261-265.

8. Lujan ME, Chizen DR, Pierson RA. Diagnostic criteria for polycystic ovary syndrome: pitfalls and controversies. J Obstet Gynaecol Can. 2008;30(8):671-679.

9. March WA, Moore VM, Willson KJ, Phillips DI, Norman RJ, Davies MJ. The prevalence of polycystic ovary syndrome in a community sample assessed under contrasting diagnostic criteria. Hum Reprod. 2010;25(2):544-551

10. Zawadzki J, Dunaif A. Diagnostic criteria for polycystic ovary syndrome: towards a rational approach. In: Dunaif A, Givens J, Haseltine F, Marrian G, editors. Polycystic Ovary Syndrome. Current Issues in Endocrinology and Metabolism. Vol 4. Boston: Blackwell Scientific; 1992.

11. Rotterdam ESHRE/ASRM-Sponsored PCOS Consensus Workshop Group. Revised 2003 consensus on diagnostic criteria and long-term health risks related to polycystic ovary syndrome. Fertil Steril. 2004;81(1):19-25.

12. Azziz R, Carmina E, Dewailly D, et al. Criteria for defining polycystic ovary syndrome as a predominantly hyperandrogenic syndrome: an Androgen Excess Society Guideline. J. Clin Endocrinol Metab. 2006;91(11):4237-4245.

13. Moran L, Teede H. Metabolic features of the reproductive phenotypes of polycystic ovary syndrome. Hum Reprod Update. 2009;15(4): 477-488.

14. Bracero N, Zacur HA. Polycystic ovary syndrome and hyperprolactinemia. Obstet Gynecol Clin North Am. 2001;28(1):77-84.

15. Filho RB, Domingues L, Naves L, Ferraz E, Alves A, Casulari LA. Polycystic ovary syndrome and hyperprolactinemia are distinct entities. Gynecol Endocrinol. 2007;23(5):267-272. 
16. Su HW, Chen CM, Chou SY, Liang SJ, Hsu CS, Hsu MI. Polycystic ovary syndrome or hyperprolactinaemia: a study of mild hyperprolactinaemia. Gynecol Endocrinol. 2011;27(1):55-62.

17. Szosland K, Pawlowicz P, Lewinski A. Prolactin secretion in polycystic ovary syndrome (PCOS). Neuro Endocrinol Lett. 2015;36(1): 53-58.

18. Chen L, Kuang J, Pei JH, et al. Continuous positive airway pressure and diabetes risk in sleep apnea patients: a systemic review and metaanalysis. Eur J Intern Med. 2017;39:39-50.

19. Ehrman DA, Barnes RB, Rosenfield RL. Polycystic ovary syndrome as a form of functional ovarian hyperandrogenism due to dysregulation of androgen secretion. Endocr Rev. 1995;16(3):322-353.

20. Christakou C, Diamanti-Kandarakis E. Polycystic ovary syndrome-phenotypes and diagnosis. Scand J Clin Lab Invest Suppl. 2014;244:18-22.

21. Tosi F, Fiers T, Kaufman JM, et al. Implications of androgen assay accuracy in the phenotyping of women with polycystic ovary syndrome. J Clin Endocrinol Metab. 2016;101(2):610-618.

22. Stepto NK, Cassar S, Joham AE, et al. Women with polycystic ovary syndrome have intrinsic insulin resistance on euglycaemic-hyperinsulaemic clamp. Hum Reprod. 2013;28(3):777-784.

23. Rajkhowa M, Brett S, Cuthbertson Daniel J, et al. Insulin resistance in polycystic ovary syndrome is associated with defective regulation of ERK1/2 by insulin in skeletal muscle in vivo. Biochem $J$. 2009;418(3):665-671.

24. Caro JF, Dohm LG, Pories WJ, Sinha MK. Cellular alterations in liver, skeletal muscle, and adipose tissue responsible for insulin resistance in obesity and type II diabetes. Diabetes Metab Rev. 1989;5(8):665-689.

25. Diamanti-Kandarakis E, Papalou O, Kandaraki EA, Kassi G. Mechanisms in endocrinology: nutrition as a mediator of oxidative stress in metabolic and reproductive disorders in women. Eur J Endocrinol. 2017;176(2):R79-R99.

26. Urbanek M, Legro RS, Driscoll DA, et al. Thirty-seven candidate genes for polycystic ovary syndrome: strongest evidence for linkage is with follistatin. Proc Natl Acad Sci U SA. 1999;96(15):8573-8578.

27. Jones MR, Goodarzi MO. Genetic determinants of polycystic ovary syndrome: progress and future directions. Fertil Steril. 2016;106(1):25-32.

28. Witchel SF, Recabarren SE, González F, et al. Emerging concepts about prenatal genesis, aberrant metabolism and treatment paradigms in polycystic ovary syndrome. Endocrine. 2012;42(3):526-534.

29. Parkinson JR, Hyde MJ, Gale C, Santhakumaran S, Modi N. Preterm birth and the metabolic syndrome in adult life: a systematic review and meta-analysis. Pediatrics. 2013;131(4):e1240-e1263.

30. Newsome CA, Shiell AW, Fall CH, Phillips DI, Shier R, Law CM. Is birth weight related to later glucose and insulin metabolism?a systematic review. Diabet Med. 2003;20(5):339-348.

31. Li S, Zhang M, Tian H, Liu Z, Yin X, Xi B. Preterm birth and risk of type 1 and type 2 diabetes: systematic review and meta-analysis. Obes Rev. 2014;15(10):804-811.

32. Davies MJ, March WA, Willson KJ, Giles LC, Moore VM. Birthweight and thinness at birth independently predict symptoms of polycystic ovary syndrome in adulthood. Hum Reprod. 2012;27(5): $1475-1480$.

33. Kennaway DJ, Flanagan DE, Moore VM, Cockington RA, Robinson JS, Phillips DI. The impact of fetal size and length of gestation on 6-sulphatoxymelatonin excretion in adult life. J Pineal Res. 2001;30(3):188-192.

34. Ward AM, Moore VM, Steptoe A, Cockington RA, Robinson JS, Phillips DI. Size at birth and cardiovascular responses to psychological stressors: evidence for prenatal programming in women. J Hypertens. 2004;22(12):2295-2301.

35. Langley-Evans SC. Nutrition in early life and the programming of adult disease: a review. J Hum Nutr Diet. 2015;28 Suppl 1:1-14.

36. Langley-Evans SC. Developmental programming of health and disease. Proc Nutr Soc. 2006;65(1):97-105.
37. Reynolds RM. Glucocorticoid excess and the developmental origins of disease: two decades of testing the hypothesis - 2012 Curt Richter Award Winner. Psychoneuroendocrinology. 2013;38(1):1-11.

38. Jenkins CD, Stanton BA, Niemcryk SJ, Rose RM. A scale for the estimation of sleep problems in clinical research. J Clin Epidemiol. 1988;41(4):313-321.

39. American Psychiatric Association. Sleep-Wake Disorders. Diagnostic and Statistical Manual of Mental Disorders, Fifth Edition (DSM-5). Arlington: American Psychiatric Association; 2013.

40. Park JG, Ramar K, Olson EJ. Updates on definition, consequences, and management of obstructive sleep apnea. Mayo Clin Proc. 2011; 86(6):549-554.

41. Epstein LJ, Kristo D, Strollo PJ Jr, et al; Adult Obstructive Sleep Apnea Task Force of the American Academy of Sleep Medicine. Clinical guideline for the evaluation, management and longterm care of obstructive sleep apnea in adults. J Clin Sleep Med. 2009;5(3):263-276.

42. Goel N, Rao H, Durmer JS, Dinges DF. Neurocognitive consequences of sleep deprivation. Semin Neurol. 2009;29(4):320-339.

43. Léger D, Bayon V. Societal costs of insomnia. Sleep Med Rev. 2010;14(6):379-389.

44. Hillman DR, Lack LC. Public health implications of sleep loss: the community burden. Med J Aust. 2013;199(8):S7-S10.

45. Bucks RS, Olaithe M, Eastwood P. Neurocognitive function in obstructive sleep apnoea: a meta-review. Respirology. 2013;18(1):61-70.

46. Lin TY, Lin PY, Su TP, et al. Risk of developing obstructive sleep apnea among women with polycystic ovarian syndrome: a nationwide longitudinal follow-up study. Sleep Med. 2017;36:165-169.

47. Hung JH, Hu LY, Tsai SJ, et al. Risk of psychiatric disorders following polycystic ovary syndrome: a nationwide population-based cohort study. PLoS One. 2014;9(5):e97041.

48. Moran LJ, March WA, Whitrow MJ, Giles LC, Davies MJ, Moore VM. Sleep disturbances in a community-based sample of women with polycystic ovary syndrome. Hum Reprod. 2015;30(2):466-472.

49. Ezeh U,Yildiz BO, Azziz R. Referral bias in defining the phenotype and prevalence of obesity in polycystic ovary syndrome. J Clin Endocrinol Metab. 2013;98(6):E1088-E1096.

50. Fogel RB, Malhotra A, Pillar G, Pittman SD, Dunaif A, White DP. Increased prevalence of obstructive sleep apnea syndrome in obese women with polycystic ovary syndrome. J Clin Endocrinol Metab. 2001;86(3):1175-1180.

51. Suri J, Suri JC, Chatterjee B, Mittal P, Adhikari T. Obesity may be the common pathway for sleep-disordered breathing in women with polycystic ovary syndrome. Sleep Med. 2016;23:32-39.

52. Tasali E, Van Cauter E, Ehrmann DA. Relationships between sleep disordered breathing and glucose metabolism in polycystic ovary syndrome. J Clin Endocrinol Metab. 2006;91(1):36-42.

53. Tasali E, Van Cauter E, Hoffman L, Ehrmann DA. Impact of obstructive sleep apnea on insulin resistance and glucose tolerance in women with polycystic ovary syndrome. J Clin Endocrinol Metab. 2008;93(10):3878-3884.

54. Vgontzas AN, Legro RS, Bixler EO, Grayev A, Kales A, Chrousos GP. Polycystic ovary syndrome is associated with obstructive sleep apnea and daytime sleepiness: role of insulin resistance. J Clin Endocrinol Metab. 2001;86(2):517-520.

55. Yang HP, Kang JH, Su HY, Tzeng CR, Liu WM, Huang SY. Apneahypopnea index in nonobese women with polycystic ovary syndrome. Int J Gynaecol Obstet. 2009;105(3):226-229.

56. de Sousa G, Schluter B, Menke T, Trowitzsch E, Andler W, Reinehr T. Relationships between polysomnographic variables, parameters of glucose metabolism, and serum androgens in obese adolescents with polycystic ovarian syndrome. J Sleep Res. 2011;20(3):472-478.

57. de Sousa G, Schluter B, Menke T, Trowitzsch E, Andler W, Reinehr T. A comparison of polysomnographic variables between adolescents with polycystic ovarian syndrome with and without the metabolic syndrome. Metab Syndr Relat Disord. 2011;9(3):191-196. 
58. de Sousa G, Schlüter B, Buschatz D, et al. A comparison of polysomnographic variables between obese adolescents with polycystic ovarian syndrome and healthy, normal-weight and obese adolescents. Sleep Breath. 2010;14(1):33-38.

59. Nandalike K, Agarwal C, Strauss T, et al. Sleep and cardiometabolic function in obese adolescent girls with polycystic ovary syndrome. Sleep Med. 2012;13(10):1307-1312.

60. Baldwin CM, Kapur VK, Holberg CJ, Rosen C, Nieto FJ; Sleep Heart Health Study Group. Associations between gender and measures of daytime somnolence in the Sleep Heart Health Study. Sleep. 2004;27(2):305-311.

61. Redline S, Kump K, Tishler PV, Browner I, Ferrette V. Gender differences in sleep disordered breathing in a community-based sample. $\mathrm{Am}$ J Respir Crit Care Med. 1994;149(3 Pt 1):722-726.

62. Franik G, Krysta K, Madej P, et al. Sleep disturbances in women with polycystic ovary syndrome. Gynecol Endocrinol. 2016;32(12): 1014-1017.

63. Borbély AA. A two process model of sleep regulation. Hum Neurobiol. 1982;1(3):195-204.

64. Institute of Medicine (US) Committee on Sleep Medicine and Research, Colten HR, Altevogt BM, editors. Sleep physiology. Sleep Disorders and Sleep Deprivation: An Unmet Public Health Problem. Washington: National Academies Press; 2006:33-53.

65. Haus E, Smolensky M. Biological clocks and shift work: circadian dysregulation and potential long-term effects. Cancer Causes Control. 2006;17(4):489-500.

66. Dibner C, Schibler U, Albrecht U. The mammalian circadian timing system: organization and coordination of central and peripheral clocks. Annu Rev Physiol. 2010;72(1):517-549.

67. Morris CJ, Aeschbach D, Scheer FA. Circadian system, sleep and endocrinology. Mol Cell Endocrinol. 2012;349(1):91-104.

68. Gamble KL, Berry R, Frank SJ, Young ME. Circadian clock control of endocrine factors. Nat Rev Endocrinol. 2014;10(8):466-475.

69. Lim SS, Davies MJ, Norman RJ, Moran LJ. Overweight, obesity and central obesity in women with polycystic ovary syndrome: a systematic review and meta-analysis. Hum Reprod Update. 2012;18(6):618-637.

70. Teede HJ, Joham AE, Paul E, et al. Longitudinal weight gain in women identified with polycystic ovary syndrome: results of an observational study in young women. Obesity (Silver Spring). 2013;21(8):1526-1532.

71. Moran LJ, Noakes M, Clifton PM, et al. Ghrelin and measures of satiety are altered in polycystic ovary syndrome but not differentially affected by diet composition. J Clin Endocrinol Metab. 2004;89(7):3337-3344.

72. Hirschberg AL, Naessen S, Stridsberg M, Bystrom B, Holtet J. Impaired cholecystokinin secretion and disturbed appetite regulation in women with polycystic ovary syndrome. Gynecol Endocrinol. 2004;19(2):79-87.

73. Zwirska-Korczala K, Sodowski K, Konturek SJ, et al. Postprandial response of ghrelin and PYY and indices of low-grade chronic inflammation in lean young women with polycystic ovary syndrome. J Physiol Pharmacol. 2008;59 Suppl 2:161-178.

74. Vrbiklova J, Hill M, Bendlova B, et al. Incretin levels in polycystic ovary syndrome. Eur J Endocrinol. 2008;159(2):121-127.

75. Georgopoulos NA, Saltamavros AD, Vervita V, et al. Basal metabolic rate is decreased in women with polycystic ovary syndrome and biochemical hyperandrogenemia and is associated with insulin resistance. Fertil Steril. 2009;92(1):250-255.

76. Robinson S, Chan SP, Spacey S, Anyaoku V, Johnston DG, Franks S. Postprandial thermogenesis is reduced in polycystic ovary syndrome and is associated with increased insulin resistance. Clin Endocrinol (Oxf). 1992;36(6):537-543.

77. Moroshko I, Brennan L, O’Brien P. Predictors of dropout in weight loss interventions: a systematic review of the literature. Obes Rev. 2011;12(11):912-934.

78. Moran LJ, Deeks AA, Gibson-Helm ME, Teede HJ. Psychological parameters in the reproductive phenotypes of polycystic ovary syndrome. Hum Reprod. 2012;27(7):2082-2088.
79. Schwartz AR, Patil SP, Laffan AM, Polotsky V, Schneider H, Smith PL. Obesity and obstructive sleep apnea: pathogenic mechanisms and therapeutic approaches. Proc Am Thorac Soc. 2008;5(2):185-192.

80. de Sousa AG, Cercato C, Mancini MC, Halpern A. Obesity and obstructive sleep apnea-hypopnea syndrome. Obes Rev. 2008;9(4):340-354.

81. Peppard PE, Young T, Palta M, Dempsey J, Skatrud J. Longitudinal study of moderate weight change and sleep-disordered breathing. JAMA. 2000;284(23):3015-3021.

82. Kositanurit W, Muntham D, Udomsawaengsup S, Chirakalwasan N. Prevalence and associated factors of obstructive sleep apnea in morbidly obese patients undergoing bariatric surgery. Sleep Breath. Epub 2017 Apr 11

83. Vgontzas AN, Bixler EO, Chrousos GP, Pejovic S. Obesity and sleep disturbances: meaningful sub-typing of obesity. Arch Physiol Biochem. 2008;114(4):224-236.

84. Bixler EO, Vgontzas AN, Lin HM, Calhoun SL, Vela-Bueno A, Kales A. Excessive daytime sleepiness in a general population sample: the role of sleep apnoea, age, obesity, diabetes, and depression. J Clin Endocrinol Metab. 2005;90(8):4510-4515.

85. Vgontzas AN, Bixler EO, Tan TL, Kantner D, Martin LF, Kales A. Obesity without sleep apnoea is associated with daytime sleepiness. Arch Intern Med. 1998;158(12):1333-1337.

86. Mokhlesi B, Scoccia B, Mazzone T, Sam S. Risk of obstructive sleep apnea in obese and nonobese women with polycystic ovary syndrome and healthy reproductively normal women. Fertil Steril. 2012;97(3):786-791.

87. Gopal M, Duntley S, Uhles M, Attarian H. The role of obesity in the increased of obstructive sleep apnea syndrome in patients with polycystic ovarian syndrome. Sleep Med. 2002;3(5):401-404.

88. Akinnusi ME, Saliba R, Porhomayon J, El-Solh AA. Sleep disorders in morbid obesity. Eur J Intern Med. 2012;23(3):219-226.

89. Shepertycky MR, Banno K, Kryger MH. Differences between men and women in the clinical presentation of patients diagnosed with obstructive sleep apnea syndrome. Sleep. 2005;28(3):309-314.

90. Ryan CM, Bradley TD. Pathogenesis of obstructive sleep apnea. J Appl Physiol (1985). 2005;99(6):2440-2450.

91. Whittle AT, Marshall I, Mortimore IL, Wraith PK, Sellar RJ, Douglas NJ. Neck soft tissue and fat distribution: comparison between normal men and women by magnetic resonance imaging. Thorax. 1999;54(4):323-328.

92. Evans DJ, Barth JH, Burke CW. Body fat topography in women with androgen excess. Int J Obes. 1988;12(2):157-162.

93. de Sousa G, Schluter B, Buschatz D, et al. The impact of insulin resistance and hyperandrogenemia on polysomnographic variables in obese adolescents with polycystic ovarian syndrome. Sleep Breath. 2012;16(1):169-175.

94. Rao MN, Neylan TC, Grunfeld C, Mulligan K, Schambelan M, Schwarz JM. Subchronic sleep restriction causes tissue-specific insulin resistance. J Clin Endocrinol Metab. 2015;100(4):1664-1671.

95. Ip MS, Lam B, Ng MM, Lam WK, Tsang KW, Lambs KS. Obstructive sleep apnea is independently associated with insulin resistance. $\mathrm{Am} \mathrm{J}$ Respir Crit Care Med. 2002;165(5):670-676.

96. Harsch IA, Schahin SP, Radespiel-Tröger M, et al. Continuous positive airway pressure treatment rapidly improves insulin sensitivity in patients with obstructive sleep apnea syndrome. Am J Respir Crit Care Med. 2004;169(2):156-162.

97. Barceló A, Barbé F, de la Peña M, et al. Insulin resistance and daytime sleepiness in patients with sleep apnoea. Thorax. 2008;63(11):946-950.

98. Balkau B, Vol S, Loko S, et al. High baseline insulin levels associated with 6-year incident observed sleep apnea. Diabetes Care. 2010;33(5):1044-1049.

99. Greco C, Spallone V. Obstructive sleep apnoea syndrome and diabetes. Fortuitous association or interaction? Curr Diabetes Rev. 2016;12(2):129-155.

100. Lansdown A, Rees DA. The sympathetic nervous system in polycystic ovary syndrome: a novel therapeutic target? Clin Endocrinol (Oxf). 2012;77(6):791-801. 
101. El-Sharkawy AA, Abdelmotaleb GS, Aly MK, Kabel AM. Effect of metformin on sleep disorders in adolescent girls with polycystic ovarian syndrome. J Pediatr Adolesc Gynecol. 2014;27(6):347-352.

102. Liu A, Kim SH, Ariel D, et al. Does enhanced insulin sensitivity improve sleep measures in patients with obstructive sleep apnea: a randomized, placebo-controlled pilot study. Sleep Med. 2016;22: $57-60$.

103. Reinehr T, Kulle A, Rothermel J, et al. Longitudinal analyses of the steroid metabolome in obese PCOS girls with weight loss. Endocr Connect. 2017;6(4):213-224.

104. Prelevic GM, Wurzburger MI, Balint-Peric L. 24-Hour serum cortisol profiles in women with polycystic ovary syndrome. Gynecol Endocrinol. 1993;7(3):179-184.

105. Kiałka M, Ociepka A, Milewicz T, et al. Evening not morning plasma cortisol level is higher in women with polycystic ovary syndrome. Przegl Lek. 2015;72(5):240-242.

106. Roelfsema F, Kok P, Pereira AM, Pijl H. Cortisol production rate is similarly elevated in obese women with or without the polycystic ovary syndrome. J Clin Endocrinol Metab. 2010;95(7):3318-3324.

107. Buckley TM, Schatzberg AF. On the interactions of the hypothalamicpituitary-adrenal (HPA) axis and sleep: normal HPA axis activity and circadian rhythm, exemplary sleep disorders. J Clin Endocrinol Metab. 2005;90(5):3106-3114.

108. Benson S, Arck PC, Tan S, et al. Disturbed stress responses in women with polycystic ovary syndrome. Psychoneuroendocrinology. 2009;34(5):727-735.

109. Meerlo P, Sgoifo A, Suchecki D. Restricted and disrupted sleep: effects on autonomic function, neuroendocrine stress systems and stress responsivity. Sleep Med Rev. 2008;12(3):197-210.

110. Garde AH, Albertsen K, Persson R, Hansen A, Rugulies R. Bidirectional associations between psychological arousal, cortisol, and sleep. Behav Sleep Med. 2012;10(1):28-40.

111. Jain P, Jain M, Haldar C, Singh TB, Jain S. Melatonin and its correlation with testosterone in polycystic ovarian syndrome. J Hum Reprod Sci. 2013;6(4):253-258.

112. Luboshitzky R, Qupti G, Ishay A, Shen-Orr Z, Futerman B, Linn S. Increased 6-sulfatoxymelatonin excretion in women with polycystic ovary syndrome. Fertil Steril. 2001;76(3):506-510.

113. Shreeve N, Cagampang F, Sadek K, et al. Poor sleep in PCOS; is melatonin the culprit? Hum Reprod. 2013;28(5):1348-1353.

114. Luboshitzky R, Herer P, Shen-Orr Z. Urinary 6-sulfatoxymelatonin excretion in hyperandrogenic women: the effect of cyproterone acetate-ethinyl estradiol treatment. Exp Clin Endocrinol Diabetes. 2004;112(2):102-107.

115. Tagliaferri V, Romualdi D, Scarinci E, et al. Melatonin treatment may be able to restore menstrual cyclicity in women with PCOS: a pilot study. Reprod Sci. Epub 2017 Jan 1.

116. Baglioni C, Battagliese G, Feige B, et al. Insomnia as a predictor of depression: a meta-analytic evaluation of longitudinal epidemiological studies. J Affect Disord. 2011;135(1-3):10-19.

117. Gupta MA, Simpson FC. Obstructive sleep apnea and psychiatric disorders: a systematic review. J Clin Sleep Med. 2015;11(2): 165-175.

118. Glidewell RN, McPherson Botts E, Orr WC. Insomnia and anxiety: diagnostic and management implications of complex interactions. Sleep Med Clin. 2015;10(1):93-99.

119. Alvaro PK, Roberts RM, Harris JK. A systematic review assessing bidirectionality between sleep disturbances, anxiety, and depression. Sleep. 2013;36(7):1059-1068.

120. Kalmbach DA, Arnedt JT, Swanson LM, Rapier JL, Ciesla JA. Reciprocal dynamics between self-rated sleep and symptoms of depression and anxiety in young adult women: a 14-day diary study. Sleep Med. 2017;33:6-12

121. Barry JA, Kuczmierczyk AR, Hardiman PJ. Anxiety and depression in polycystic ovary syndrome: a systematic review and meta-analysis. Hum Reprod. 2011;26(9):2442-2451.
122. Blay SL, Aguiar JVA, Passos IC. Polycystic ovary syndrome and mental disorders: a systematic review and exploratory meta-analysis. Neuropsychiatr Dis Treat. 2016;12:2895-2903.

123. Dokras A, Clifton S, Futterweit W, Wild R. Increased risk for abnormal depression scores in women with polycystic ovary syndrome: a systematic review and meta-analysis. Obstet Gynecol. 2011;117(1):145-152.

124. Dokras A, Clifton S, Futterweit W, Wild R. Increased prevalence of anxiety symptoms in women with polycystic ovary syndrome: systematic review and meta-analysis. Fertil Steril. 2012;97(1):225-230.

125. Veltman-Verhulst SM, Boivin J, Eijkemans MJ, Fauser BJ. Emotional distress is a common risk in women with polycystic ovary syndrome: a systematic review and meta-analysis of 28 studies. Hum Reprod Update. 2012;18(6):638-651.

126. Weiner CL, Primeau M, Ehrmann DA. Androgens and mood dysfunction in women: comparison of women with polycystic ovarian syndrome to healthy controls. Psychosom Med. 2004;66(3):356-362.

127. Bloch M, Daly RC, Rubinow DR. Endocrine factors in the etiology of postpartum depression. Compr Psychiatry. 2003;44(3):234-246.

128. Dedovic K, Ngiam J. The cortisol awakening response and major depression: examining the evidence. Neuropsychiatr Dis Treat. 2015;11:1181-1189.

129. Naqvi SH, Moore A, Bevilacqua K, et al. Predictors of depression in women with polycystic ovary syndrome. Arch Womens Ment Health. 2015;18(1):95-101.

130. Jedel E, Waern M, Gustafson D, et al. Anxiety and depression symptoms in women with polycystic ovary syndrome compared with controls matched for body mass index. Hum Reprod. 2010;25(2):450-456.

131. Chen X, Gelaye B, Williams MA. Sleep characteristics and healthrelated quality of life among a national sample of American young adults: assessment of possible health disparities. Qual Life Res. 2014;23(2):613-625.

132. Medic G, Wille M, Hemels ME. Short- and long-term health consequences of sleep disruption. Nat Sci Sleep. 2017;9:151-161.

133. Li Y, Li Y, Yu Ng EH, et al. Polycystic ovary syndrome is associated with negatively variable impacts on domains of health-related quality of life: evidence from a meta-analysis. Fertil Steril. 2011;96(2):452-458.

134. Kaczmarek C, Haller DM, Yaron M. Health-related quality of life in adolescents and young adults with polycystic ovary syndrome: a systematic review. J Pediatr Adolesc Gynecol. 2016;29(6):551-557.

135. Chachamovich JR, Chachamovich E, Ezer H, Fleck MP, Knauth D, Passos EP. Investigating quality of life and health-related quality of life in infertility: a systematic review. J Psychosom Obstet Gynaecol. 2010;31(2):101-110.

136. Elsenbruch S, Hahn S, Kowalsky D, et al. Quality of life, psychosocial well-being, and sexual satisfaction in women with polycystic ovary syndrome. J Clin Endocrinol Metab. 2003;88(12):5801-5807.

137. Pastore LM, Patrie JT, Morris WL, Dalal P, Bray MJ. Depression symptoms and body dissatisfaction association among polycystic ovary syndrome women. J Psychosom Res. 2011;71(4):270-276.

138. Trent ME, Rich M, Austin SB, Gordon CM. Quality of life in adolescent girls with polycystic ovary syndrome. Arch Pediatr Adolesc Med. 2002;156(6):556-560.

139. Mehari A, Weir NA, Gillum RF. Gender and the association of smoking with sleep quantity and quality in American adults. Women Health. 2014;54(1):1-14.

140. Garcia AN, Salloum IM. Polysomnographic sleep disturbances in nicotine, caffeine, alcohol, cocaine, opioid, and cannabis use: a focused review. Am J Addict. 2015;24(7):590-598.

141. Thakkar MM, Sharma R, Sahota P. Alcohol disrupts sleep homeostasis. Alcohol. 2015;49(4):299-310.

142. Zomers ML, Hulsegge G, van Oostrom SH, Proper KI, Verschuren WM, Picavet HSJ. Characterizing adult sleep behavior over 20 years - the population-based Doetinchem Cohort Study. Sleep. 2017;40(7).

143. Chen LJ, Steptoe A, Chen YH, Ku PW, Lin CH. Physical activity, smoking, and the incidence of clinically diagnosed insomnia. Sleep Med. 2017;30:189-194. 
144. Rubio-Arias JÁ, Marín-Cascales E, Ramos-Campo DJ, Hernandez AV, Pérez-López FR. Effect of exercise on sleep quality and insomnia in middle-aged women: a systematic review and meta-analysis of randomized controlled trials. Maturitas. 2017;100:49-56.

145. Lang C, Kalak N, Brand S, Holsboer-Trachsler E, Pühse U, Gerber M. The relationship between physical activity and sleep from mid adolescence to early adulthood. A systematic review of methodological approaches and meta-analysis. Sleep Med Rev. 2016;28:32-45.

146. Norman RJ, Davies MJ, Lord J, Moran LJ. The role of lifestyle modification in polycystic ovary syndrome. Trends Endocrinol Metab. 2002;13(6):251-257.

147. Strine TW, Chapman DP, Ahluwalia IB. Menstrual-related problems and psychological distress among women in the United States. J Womens Health (Larchmt). 2005;14(4):316-323.

148. Banting LK, Gibson-Helm M, Polman R, Teede HJ, Stepto NK. Physical activity and mental health in women with polycystic ovary syndrome. BMC Womens Health. 2014;14(1):51.

149. Harrison CL, Lombard CB, Moran LJ, Teede HJ. Exercise therapy in polycystic ovary syndrome: a systematic review. Hum Reprod Update. 2011;17(2):171-183.

150. Bacchi E, Negri C, Di Sarra D, et al. Serum testosterone predicts cardiorespiratory fitness impairment in normal-weight women with polycystic ovary syndrome. Clin Endocrinol (Oxf). 2015;83(6):895-901.

151. Wang ET, Ku IA, Shah SJ, et al. Polycystic ovary syndrome is associated with higher left ventricular mass index: the CARDIA women's study. J Clin Endocrinol Metab. 2012;97(12):4656-4662.

152. Wang ET, Calderon-Margalit R, Cedars MI, et al. Polycystic ovary syndrome and risk for long-term diabetes and dyslipidemia. Obstet Gynecol. 2011;117(1):6-13.

153. Calderon-Margalit R, Siscovick D, Merkin SS, et al. Prospective association of polycystic ovary syndrome with coronary artery calcification and carotid-intima-media thickness: the coronary artery risk development in young adults women's study. Arterioscler Thromb Vasc Biol. 2014;34(12):2688-2694.

154. Hart R, Doherty DA. The potential implications of a PCOS diagnosis on a woman's long-term health using data linkage. J Clin Endocrinol Metab. 2015;100(3):911-919.

155. Wild S, Pierpoint T, Jacobs H, McKeigue P. Long-term consequences of polycystic ovary syndrome: results of a 31 year follow-up study. Hum Fertil (Camb). 2000;3(2):101-105.

156. Schmidt J, Landin-Wilhelmsen K, Brännström M, Dahlgren E. Cardiovascular disease and risk factors in PCOS women of postmenopausal age: a 21-year controlled follow-up study. J Clin Endocrinol Metab. 2011;96(12):3794-3803

157. Anothaisintawee T, Reutrakul S, Van Cauter E, Thakkinstian A Sleep disturbances compared to traditional risk factors for diabetes development: systematic review and meta-analysis. Sleep Med Rev. 2016;30:11-24.

158. McHill AW, Wright KP Jr. Role of sleep and circadian disruption on energy expenditure and in metabolic predisposition to human obesity and metabolic disease. Obes Rev. 2017;18 Suppl 1:15-24.

159. Brondel L, Romer MA, Nougues PM, Touyarou P, Davenne D. Acute partial sleep deprivation increases food intake in healthy men. $\mathrm{Am} \mathrm{J}$ Clin Nutr. 2010;91(6):1550-1559.

160. Spaeth AM, Dinges DF, Goel N. Effects of experimental sleep restriction on weight gain, caloric intake, and meal timing in healthy adults. Sleep. 2013;36(7):981-990.

161. Nedeltcheva AV, Kilkus JM, Imperial J, Schoeller DA, Penev PD. Insufficient sleep undermines dietary efforts to reduce adiposity. Ann Intern Med. 2010;153(7):435-441.

162. Spiegel K, Leproult R, Van Cauter E. Impact of sleep debt on metabolic and endocrine function. Lancet. 1999;354(9188):1435-1439.

163. Buxton OM, Pavlova M, Reid EW, Wang W, Simonson DC, Adler GK. Sleep restriction for 1 week reduces insulin sensitivity in healthy men. Diabetes. 2010;59(9):2126-2133.
164. Punjabi NM, Shahar E, Redline S, Gottlieb DJ, Givelber R, Resnick HE; Sleep Heart Health Study Investigators. Sleep-disordered breathing, glucose intolerance, and insulin resistance: the sleep heart health study. Am J Epidemiol. 2004;160(6):521-530.

165. Shaw JE, Punjabi NM, Wilding JP, Alberti KG, Zimmet PZ; International Diabetes Federation Taskforce on Epidemiology and Prevention. Sleep-disordered breathing and type 2 diabetes: a report from the International Diabetes Federation Taskforce on Epidemiology and Prevention. Diabetes Res Clin Pract. 2008;81(1):2-12.

166. Gonzaga C, Bertolami A, Bertolami M, Amodeo C, Calhoun D. Obstructive sleep apnea, hypertension and cardiovascular diseases. J Hum Hypertens. 2015;29(12):705-712.

167. Hecht L, Möhler R, Meyer G. Effects of CPAP-respiration on markers of glucose metabolism in patients with obstructive sleep apnoea syndrome: a systematic review and meta-analysis. Ger Med Sci. 2011;9:Doc20.

168. Marin JM, Carrizo SJ, Vicente E, Agusti AG. Long-term cardiovascular outcomes in men with obstructive sleep apnoea-hypopnoea with or without treatment with continuous positive airway pressure: an observational study. Lancet. 2005;365(9464):1046-1053.

169. Peppard PE, Young T, Palta M, Skatrud J. Prospective study of the association between sleep-disordered breathing and hypertension. N Engl J Med. 2000;342(19):1378-1384.

170. Doonan RJ, Scheffler P, Lalli M, et al. Increased arterial stiffness in obstructive sleep apnea: a systematic review. Hypertens Res. 2011;34(1):23-32.

171. Drager LF, Polotsky VY, Lorenzi-Filho G. Obstructive sleep apnea: an emerging risk factor for atherosclerosis. Chest. 2011;140(2):534-542.

172. Chatterjee B, Suri J, Suri JC, Mittal P, Adhikari T. Impact of sleepdisordered breathing on metabolic dysfunctions in patients with polycystic ovary syndrome. Sleep Med. 2014;15(12):1547-1553.

173. Lack L, Sweetman A. Diagnosis and treatment of insomnia comorbid with obstructive sleep apnea. Sleep Med Clin. 2016;11(3):379-388.

174. Joosten SA, Hamilton GS, Naughton MT. Impact of weight loss management in OSA. Chest. 2017;152(1):194-203.

175. Benson S, Hahn S, Tan S, Janssen OE, Schedlowski M, Elsenbruch S. Maladaptive coping with illness in women with polycystic ovary syndrome. J Obstet Gynecol Neonatal Nurs. 2010;39(1):37-45.

176. Tasali E, Chapotot F, Leproult R, Whitmore H, Ehrmann DA. Treatment of obstructive sleep apnea improves cardiometabolic function in young obese women with polycystic ovary syndrome. J Clin Endocrinol Metab. 2011;96(2):365-374.

177. Wang J, Yu W, Gao M, et al. Impact of obstructive sleep apnea syndrome on endothelial function, arterial stiffening, and serum inflammatory markers: an updated meta-analysis and metaregression of 18 studies. J Am Heart Assoc. 2015;4(11).

178. Sun Y, Huang ZY, Sun QR, Qiu LP, Zhou TT, Zhou GH. CPAP therapy reduces blood pressure for patients with obstructive sleep apnoea: an update meta-analysis of randomized clinical trials. Acta Cardiol. 2016;71(3):275-280.

179. Schwarz EI, Puhan MA, Schlatzer C, Stradling JR, Kohler M. Effect of CPAP therapy on endothelial function in obstructive sleep apnoea: a systematic review and meta-analysis. Respirology. 2015;20(6):889-895.

180. Xu H, Wang Y, Guan J, Yi H, Yin S. Effect of CPAP on endothelial function in subjects with obstructive sleep apnea: a meta-analysis. Respir Care. 2015;60(5):749-755.

181. Gildeh N, Rosenzweig I, Kent BD. Lessons from randomised controlled trials of continuous positive airways pressure therapy in the prevention of cardiovascular morbidity and mortality. $J$ Thorac Dis. 2017;9(2):244-246.

182. Povitz M, Bolo CE, Heitman SJ, Tsai WH, Wang J, James MT. Effect of treatment of obstructive sleep apnea on depressive symptoms: systematic review and meta-analysis. PLoS Med. 2014;11(11):e1001762.

183. McEvoy RD, Antic NA, Heeley E, et al. CPAP for prevention of cardiovascular events in obstructive sleep apnea. $N$ Engl J Med. 2016;375(10):919-931. 
184. Qaseem A, Kansagara D, Forciea MA, Cooke M, Denberg TD; Clinical Guidelines Committee of the American College of Physicians. Management of chronic insomnia disorder in adults: a clinical practice guideline from the American College of Physicians. Ann Intern Med. 2016;165(2):125-133.

185. Wilson SJ, Nutt DJ, Alford C, et al. British Association for Psychopharmacology consensus statement on evidence-based treatment of insomnia, parasomnias and circadian rhythm disorders. JPsychopharmacol. 2010;24(11):1577-1601.

186. van Straten A, van der Zweerde T, Kleiboer A, Cuijpers P, Morin CM, Lancee J. Cognitive and behavioral therapies in the treatment of insomnia: a meta-analysis. Sleep Med Rev. Epub 2017 Feb 9.

187. Morin CM, Culbert JP, Schwartz SM. Nonpharmacological interventions for insomnia: a meta-analysis of treatment efficacy. Am J Psychiatry. 1994;151(8):1172-1180.

188. Murtagh DR, Greenwood KM. Identifying effective psychological treatments for insomnia: a meta-analysis. J Consult Clin Psychol. 1995;63(1):79-89.

189. Wu JQ, Appleman ER, Salazar RD, Ong JC. Cognitive behavioral therapy for insomnia comorbid with psychiatric and medical conditions: a meta-analysis. JAMA Intern Med. 2015;175(9):1461-1472.
190. Ye YY, Chen NK, Chen J, et al. Internet-based cognitive-behavioural therapy for insomnia (ICBT-i): a meta-analysis of randomised controlled trials. BMJ Open. 2016;6(11):e010707.

191. Seyffert M, Lagisetty P, Landgraf J, et al. Internet-delivered cognitive behavioral therapy to treat insomnia: a systematic review and metaanalysis. PLoS One. 2016;11(2):e0149139.

192. Falloon K, Arroll B, Elley CR, Fernando A 3rd. The assessment and management of insomnia in primary care. BMJ. 2011;342: d2899.

193. Irish LA, Kline CE, Gunn HE, Buysse DJ, Hall MH. The role of sleep hygiene in promoting public health: a review of empirical evidence. Sleep Med Rev. 2015;22:23-36.

194. Ong JC, Shapiro SL, Manber R. Combining mindfulness meditation with cognitive-behavior therapy for insomnia: a treatment-development study. Behav Ther. 2008;39(2):171-182.

195. Teede HJ, Misso ML, Deeks AA, et al; Guideline Development Groups. Assessment and management of polycystic ovary syndrome: summary of an evidence-based guideline. Med J Aust. 2011;195(6): S65-S112.
Nature and Science of Sleep

\section{Publish your work in this journal}

Nature and Science of Sleep is an international, peer-reviewed, open access journal covering all aspects of sleep science and sleep medicine, including the neurophysiology and functions of sleep, the genetics of sleep, sleep and society, biological rhythms, dreaming, sleep disorders and therapy, and strategies to optimize healthy sleep. The manuscript

\section{Dovepress}

management system is completely online and includes a very quick and fair peer-review system, which is all easy to use. Visit http://www. dovepress.com/testimonials.php to read real quotes from published authors. 